\title{
Dynamic Impairment of Olfactory Behavior and Signaling Mediated by an Olfactory Corticofugal System
}

\author{
Renata Medinaceli Quintela, Jennifer Bauer, Lutz Wallhorn, ${ }^{\circledR}$ Kim Le, Daniela Brunert, and \\ ${ }^{-}$Markus Rothermel \\ Department of Chemosensation, AG Neuromodulation, Institute for Biology II, RWTH Aachen University, Aachen, 52074, Germany
}

Processing of olfactory information is modulated by centrifugal projections from cortical areas, yet their behavioral relevance and underlying neural mechanisms remain unclear in most cases. The anterior olfactory nucleus (AON) is part of the olfactory cortex, and its extensive connections to multiple upstream and downstream brain centers place it in a prime position to modulate early sensory information in the olfactory system. Here, we show that optogenetic activation of AON neurons in awake male and female mice was not perceived as an odorant equivalent cue. However, AON activation during odorant presentation reliably suppressed behavioral odor responses. This AON-mediated effect was fast and constant across odors and concentrations. Likewise, activation of glutamatergic AON projections to the olfactory bulb $(\mathrm{OB})$ transiently inhibited the excitability of mitral/tufted cells (MTCs) that relay olfactory input to the cortex. Single-unit MTC recordings revealed that optogenetic activation of glutamatergic AON terminals in the OB transiently decreased sensory-evoked MTC spiking, regardless of the strength or polarity of the sensory response. The reduction in MTC firing during optogenetic stimulation was confirmed in recordings in awake mice. These findings suggest that glutamatergic AON projections to the OB impede early olfactory signaling by inhibiting $\mathrm{OB}$ output neurons, thereby dynamically gating sensory throughput to the cortex.

Key words: behavior; electrophysiology; olfaction; optogenetics; sensory processing; top-down systems

Significance Statement

The anterior olfactory nucleus (AON) as an olfactory information processing area sends extensive projections to multiple brain centers, but the behavioral consequences of its activation have been scarcely investigated. Using behavioral tests in combination with optogenetic manipulation, we show that, in contrast to what has been suggested previously, the AON does not seem to form odor percepts but instead suppresses behavioral odor responses across odorants and concentrations. Furthermore, this study shows that AON activation inhibits olfactory bulb output neurons in both anesthetized as well as awake mice, pointing to a potential mechanism by which the olfactory cortex can actively and dynamically gate sensory throughput to higher brain centers.

Received Nov. 10, 2019; revised June 30, 2020; accepted July 5, 2020.

Author contributions: R.M.Q., J.B., L.W., K.L., D.B., and M.R. performed research; R.M.Q., J.B., L.W., K.L., D.B., and M.R. analyzed data; R.M.Q., J.B., L.W., D.B., and M.R. wrote the first draft of the paper; D.B. and M.R. designed research; D.B. and M.R. edited the paper; M.R. wrote the paper.

The authors declare no competing financial interests.

This work was supported by Deutsche Forschungsgemeinschaft R04046/2-1 and /2-2, Emmy Noether Program to M.R., Research Training Group 2416 "MultiSenses-MultiScales: Novel approaches to decipher neural processing in multisensory integration" 368482240/GRK2416, and Interdisciplinary Center for Clinical Research within the faculty of Medicine at the RWTH Aachen University Grant IZKF TN1-7532007. Chrna7-Cre mice were generated with funding from National Institutes of Health AG017517 to Scott W. Rogers Initial data were acquired in Utah. We thank Scott W. Rogers and Petr Tvrdik for kindly providing the Chrna7-Cre mice; the Technical Workshop at the Institute for Biology II, RWTH Aachen for excellent technical support; Matt Wachowiak, Jeremy C. McIntyre, and all members of the M.R. laboratory for helpful discussion and comments on the manuscript; and Drs. Looger, Akerboom, and Kim and the Genetically Encoded Calcium Indicator Project at Janelia Farm Research Campus in collaboration with Penn Vector Core for providing with GCaMP-expressing viruses.

Correspondence should be addressed to Markus Rothermel at m.rothermel@sensorik.rwth-aachen.de.

https://doi.org/10.1523/JNEUROSCI.2667-19.2020

Copyright $\odot 2020$ the authors

\section{Introduction}

The ability to perceive external information via sensory systems is crucial for an animal to navigate and survive in a complex environment. In a classical view, the brain processes sensory information solely based on a hierarchical organization where sensory information is shaped and refined by subsequent processing steps. However, to guarantee appropriate, flexible, and fast reactions in a rapidly changing environment, it is beneficial to implement additional mechanisms that modulate information in a situation-dependent fashion. One way to do so are cortical topdown projections, where sensory information is received from sensory cortices, and processed information is then transmitted to downstream centers to modulate incoming sensory signals. Understanding the neural mechanisms underlying sensory perception thus requires information on the neural circuits involved in both bottom-up and top-down mechanisms.

One prominent center of cortical top-down projections in olfaction is the anterior olfactory nucleus (AON), an olfactory 
cortical area located in the forebrain just caudally of the olfactory bulb (OB), the first relay station of olfactory signals within the brain. The AON can be divided into two distinct zones, pars externa, a thin ring of cells in the rostral part of the AON, and pars principalis containing the majority of AON cells (Valverde et al., 1989; Brunjes et al., 2005). Its extensive connectivity with primary and secondary processing centers (see Brunjes et al., 2005) and its position as both a "bottom-up" relay of ascending sensory input from the OB and a source of "top-down" input to the $\mathrm{OB}$ renders the $\mathrm{AON}$ an interesting model system for investigating higher-order olfactory processing and the interplay of ascending and descending information.

The AON is the largest source of cortical projections to the OB (Carson, 1984; Shipley and Adamek, 1984). AON-derived axons have been shown to project to multiple layers of the OB (Reyher et al., 1988; Padmanabhan et al., 2016; Wen et al., 2019). This includes the granule cell layer, which contains the majority of inhibitory interneurons of the $\mathrm{OB}$, as well as the layers containing the output neurons of the $\mathrm{OB}$, the external plexiform, and the mitral cell layer. Furthermore, AON projections are bilateral; that is, the AON does not only send axons to the ipsilateral but also, via the anterior commissure, to the contralateral OB (Brunjes et al., 2005; Illig and Eudy, 2009; Wen et al., 2019). Similar to cortical back projections from piriform cortex (Boyd et al., 2015; Otazu et al., 2015), the AON was shown to send sensory-evoked feedback to the OB (Rothermel and Wachowiak, 2014).

The AON has been implicated in a range of different functions, including serving as the first site of integrated odor percept formation (Haberly, 2001; Wilson and Sullivan, 2011), olfactory memory (Haberly, 2001; Aqrabawi and Kim, 2018b, 2020; Levinson et al., 2020), social interaction (Wacker et al., 2011; Oettl et al., 2016; Wang et al., 2020), controlling food intake (Soria-Gomez et al., 2014), and integrating activity within and between the two OBs (Schoenfeld and Macrides, 1984; Lei et al., 2006; Yan et al., 2008; Kikuta et al., 2010; Esquivelzeta Rabell et al., 2017; Grobman et al., 2018). Despite this wide variety of proposed functions, the exact role of centrifugal AON projections in modulating ongoing $\mathrm{OB}$ activity remains poorly characterized. Only a few studies have investigated the influence of centrifugal AON projections on $\mathrm{OB}$ circuit function (Markopoulos et al., 2012; Oettl et al., 2016; Grobman et al., 2018) demonstrating that AON inputs can depolarize as well as inhibit mitral/tufted cells (MTCs).

In the present study, we used optogenetic AON stimulation to decipher AON effects on odor-related behavior. Whereas AON stimulation was not perceived as an odor equivalent cue, AON activation during odorant presentation reliably suppressed behavioral odor responses. This effect was constant across odors and concentrations. Optical AON stimulation in anesthetized as well as in awake mice resulted in a substantial decrease in MTC spiking during sensory stimulus presentation matching the behavioral results. These findings support the hypothesis that the AON acts as a strong regulator of olfactory information transmitted to higher brain areas.

\section{Materials and Methods}

\section{Animals strain and care}

We used a mouse line (Chrna7-Cre, kindly provided by S. Rogers and P. Tvrdik, University of Utah) in which an IRES-Cre bicistronic cassette was introduced into the $3^{\prime}$ noncoding region of the cholinergic nicotinic receptor alpha7 (Chrna7) (Rogers and Gahring, 2012; Rogers et al., 2012a,b; Gahring et al., 2013). Animals of either sex were used. Animals were housed under standard conditions in ventilated racks. Mouse colonies were bred and maintained at RWTH Aachen University animal care facilities. Food and water were available ad libitum unless otherwise noted. All experimental protocols were approved by local authorities and comply with European Union legislation and recommendations by the Federation of European Laboratory Animal Science.

\section{Viral vectors}

Viral vectors were obtained from the viral vector core of the University of Pennsylvania or Addgene. Vectors were from stock batches available for general distribution. pAAV-EF1a-double floxed-hChR2(H134R)EYFP-WPRE-HGHpA (Addgene viral prep \#20298-AAV1; http://n2t. net/addgene:20298; RRID:Addgene_20298) and pAAV-Ef1a-DIO EYFP (Addgene viral prep \#27056-AAV1; http://n2t.net/addgene:27056; RRID:Addgene_27056) were a gift from Karl Deisseroth. pAAV.Syn. Flex.GCaMP6s.WPRE.SV40 was a gift from Douglas Kim \& GENIE Project (Addgene viral prep \#100845-AAV1; http://n2t.net/addgene: 100845; RRID:Addgene_100845). Injection of Cre-dependent vector (AAV1.EF1a.DIO.hChR2(H134R)-eYFP.WPRE.hGH (AAV.FLEX.ChR2. YFP), AAV-Ef1a-DIO EYFP (AAV.FLEX.EYPF), pAAV.Syn.Flex. GCaMP6s.WPRE.SV40 (AAV.FLEX. GCaMP6s) was performed as described previously (Wachowiak et al., 2013; Rothermel et al., 2014). Briefly, AON virus injection in adult ( $\geq 6$ weeks) homozygous Chrna7Cre mice was performed using stereotaxic targeting (relative to bregma: $2.8 \mathrm{~mm}$ anteroposterior, $1.25 \mathrm{~mm}$ mediolateral, $-2.7 \mathrm{~mm}$ dorsoventral) (Rothermel and Wachowiak, 2014). Virus $\left(0.5 \mu \mathrm{l}\right.$; titer $\left.1.9 \times 10^{12}\right)$ was delivered unilaterally or bilaterally through a 26 -gauge metal needle at a rate of $0.1 \mu \mathrm{l} / \mathrm{min}$. Mice were individually housed for at least $30 \mathrm{~d}$ before evaluating for transgene expression or recording.

\section{Olfactometry}

Odorants were presented as dilutions from saturated vapor in cleaned, humidified air using a custom olfactometer under computer control (Bozza et al., 2004; Verhagen et al., 2007; Rothermel et al., 2014). Odorants were typically presented for 4-10 s. All odorants were obtained at $95 \%-99 \%$ purity from Sigma Millipore and stored under nitrogen/argon. The following monomolecular odorants were used: isoamyl acetate (IAA), methyl valerate, ethyl butyrate (EB), ethyl tiglate (ET), sec-butyl acetate (secBA), methyl caproate $(\mathrm{MH}), 2$-hexanone, 2-heptanone, cyclohexylamine, valeraldehyde (VA), propyl butyrate, 2-pentanone, ethyl acetate, isopropyl butyrate, 4-methylanisole, 2-methylbutyraldehyde, methyl benzoate, vinyl butyrate, hexanal (Hex), and Mix4 (2-hexanone, sec-butyl acetate, ethyl butyrate, methyl valerate). The concentration of the odorants ranged from $0.1 \%$ to $4.5 \%$ saturated vapor.

\section{Awake, head-fixed preparation}

Behavioral testing in awake, head-fixed mice was adapted from previously described protocols (Wachowiak et al., 2013). For behavioral experiments, we expressed AAV.FLEX.ChR2.EYFP in the AON of Chrna7 animals as previously described. A custom head bolt was affixed to the skull with its posterior edge at lambda using dental acrylic. An optic fiber (low OH, $200 \mu \mathrm{m}$ core, 0.39 NA; FT200EMT, Thorlabs) was cut with a diamond knife and inserted into a 1.25 -mm-diameter ceramic ferrule (CFLC230, Thorlabs) with a $230 \mu \mathrm{m}$ bore. The optic fiber was adhered to the ferrule with epoxy (Epoxy 353ND Kit, Precision Fiber Products). The tip of the optic fiber was finely ground with polishing sandpaper and a grinding puck (D50-L, Thorlabs). After viral injection, the optic fiber was implanted into the targeted brain region under the guidance of a stereotactic device and a cannula holder (XCL, Thorlabs) (same coordinates as above, except the fiber was positioned slightly dorsal to the injection site). To secure the implanted optic fiber, dental cement was applied to the skull surface. After complete solidification of the dental cement, the cannula holder was removed from the implanted optic fiber. In control mice, viral injection was either omitted or AAV. FLEX.EYPF was used. All steps were performed in a single surgical procedure under isoflurane anesthesia. Aseptic techniques were used throughout the procedure, and local anesthetic (bupivacaine, 1\%; Sigma Millipore) was applied to all incision areas. 
Behavioral testing and optical stimulation

Experiments were performed in a custom-built behavioral setup. Odorant presentation, water delivery, optical stimulation, and data acquisition triggers were controlled with custom software written in LabView (National Instruments). All mice ( $n=19: 12$ ChR2 and 7 control animals) were initially trained on a simple lick/no-lick task structure. Behavioral training began 10-11 d after head bolt and optic fiber surgery. Mice were water-deprived to $\sim 85 \%$ of baseline body weight and gradually habituated to run on a free-floating Styrofoam ball in daily sessions. Persistent limb movement or attenuated respiration was used as an indicator of stress, in which case the session was terminated. An odor delivery port was positioned $\sim 5 \mathrm{~mm}$ in front of the animal's snout, and a lick spout was made available for water delivery. During the initial phases of training, mice were allowed to lick for a small water reward $(\sim 5-6 \mu \mathrm{l})$ at increasing intertrial intervals (5-10 s, Phase I and II). After acclimation, odorants were added to the training sessions (4 s duration, Phase III). During this phase, odorants (typically one per session) were passively presented and not rewarded.

Finally, mice were trained in a go/no-go odor paradigm (Phase IV). Mice discriminated rewarded odorants $\left(\mathrm{S}^{+}\right)$from clean air ( $\mathrm{S}^{-}$, "blank") by licking the lick spout in response to the $\mathrm{S}^{+}$and refraining from licking to the $\mathrm{S}^{-}$. In each behavioral session, 4-8 odorants (randomly picked out of a repertoire of 36 total odorants) were applied in random order. $\mathrm{S}^{+} / \mathrm{S}^{-}$presentation was also randomized (50/50 distribution). Odorants were presented for $4 \mathrm{~s}$ at a concentration of $0.5 \%$ (unless stated otherwise) with an intertrial interval varying randomly from 15 to $24 \mathrm{~s}$. Incorrect licking (false alarms) at any time during presentation of the $\mathrm{S}^{-}$ was punished with a $7 \mathrm{~s}$ increase in the following intertrial interval. Mice were tested in a single daily session (range: 50-210 trials [each $\mathrm{S}^{+}$or $\mathrm{S}^{-}$ presentation is defined as one trial]; 30-90 min). Analysis of behavioral data was performed using custom scripts in MATLAB. A response on a $\mathrm{S}^{+}$trial (hit) and no response during an $\mathrm{S}^{-}$trial (correct rejection) were categorized as correct responses during data analysis; no response on a $\mathrm{S}^{+}$trial (miss) or a response during an $\mathrm{S}^{-}$trial (false alarm) was categorized as an incorrect response. Performance accuracy was calculated as odor hits + correct rejections/number of trials. Animals had to reach performance accuracy $>80 \%$ before being tested further.

Mice were tested in the following paradigms: optogenetic stimulation in blank trials. The go/no-go odor paradigm (Phase IV) was modified such that, in $\sim 10 \%$ of $\mathrm{S}^{+}$trials, a blank was presented and licking to these trials would have been rewarded. AON photostimulation ( $4 \mathrm{~s}$ duration, unilateral or bilateral) was coupled to a subpopulation of $\mathrm{S}^{+}$blank trials. Optical stimulation trials were randomly interspersed with trials with no stimulation $\left(\mathrm{S}^{+}\right.$and $\mathrm{S}^{-}$). On average, $11.5 \pm 0.57$ (mean \pm SEM) optical stimulation trials were applied in one behavioral session. Photostimulation intensity was gradually increased from trial to trial (range 1-10 mW). Photostimulation light (delivered via a $200 \mu \mathrm{m}$ optical fiber positioned at AON; as described above) was generated by a $473 \mathrm{~nm}$ DPSS laser (VM-TIM, 07745). The optical stimulation protocol was adopted from a pulse protocol previously established for optical piriform cortex stimulation (Choi et al., 2011) (25 ms pulses repeated at $20 \mathrm{~Hz}$ for $4 \mathrm{~s}$, maximal power $10 \mathrm{~mW}$ ). Three additional pulse protocols were tested in blank photostimulation trials: $5 \mathrm{~ms}$ pulses $50 \mathrm{~Hz}, 15 \mathrm{~ms}$ pulses $50 \mathrm{~Hz}$, and $10 \mathrm{~ms}$ pulses $20 \mathrm{~Hz}$ using a power between 1 and $13 \mathrm{~mW}$. Lick responses in blank/blank + photostimulation trials were measured in percentage of total trials in this condition. Performance accuracy in this and all following paradigms was calculated as described above from nonstimulated trials and is always provided as a measure of performance and motivation of a particular animal in a task.

Optogenetic stimulation in odor trials. The go/no-go odor paradigm (Phase IV) was modified such that AON photostimulation was coupled to a subpopulation of $\mathrm{S}^{+}$odor trials (same parameters as above). For that, one odor was chosen and AON photostimulation (unilateral or bilateral) was coapplied with that particular odor (4 s duration, starting simultaneously). Selected odors changed between sessions. Optical stimulation trials were randomly interspersed with trials with no stimulation $\left(\mathrm{S}^{+}\right.$and $\left.\mathrm{S}^{-}\right)$. Photostimulation intensity was gradually increased from trial to trial (range 1-10 $\mathrm{mW}$ ). Unless noted otherwise, all photostimulation trials before odor suppression are categorized as subthreshold stimulations. Lick responses in odor + subthreshold/suprathreshold photostimulation trials were measured in percentage of total trials in this condition.

Optogenetic stimulation of different odors in one session. The "Optogenetic stimulation in odor trials" paradigm was modified so that after suprathreshold intensity was determined for one randomly chosen odorant, AON photostimulation was coapplied with different odorants within one session. Lick responses in odor + subthreshold/suprathreshold photostimulation trials were measured in percentage of total individual odorant trials.

Optogenetic stimulation in odor concentration trials. The "Optogenetic stimulation in odor trials" paradigm was modified: the minimal light intensity for inhibiting odor detection at a concentration of $0.5 \%$ was determined. Using this intensity, the odor concentration was gradually increased (range $0.5 \%-4.5 \%$ ). The lick delay (seconds, mean \pm SD) of photostimulated ChR2 and control mice was determined for each tested odorant concentration ( $4 \mathrm{~s}=$ no lick).

Decreasing the optical stimulation length relative to odor presentation. The "Optogenetic stimulation in odor trials" paradigm was modified: after suprathreshold intensity was determined for one randomly chosen odorant, the overlap between laser and odor stimulation was varied (while still starting simultaneously) ( $2 \mathrm{~s}$ laser, $4 \mathrm{~s}$ odor; $3 \mathrm{~s}$ laser, $6 \mathrm{~s}$ odor; $4 \mathrm{~s}$ laser, $6 \mathrm{~s}$ odor). Lick delays of ChR2 mice were compared with control animals (lick delay, seconds, mean $\pm \mathrm{SD}$ ).

Novel odor trials. The go/no-go odor paradigm (Phase IV) was modified such that a novel odorant was applied for the first time. The number of trials until the animal started licking to this novel odorant was determined.

Optogenetic stimulation in $\mathrm{S}^{-}$odor trials. A new cohort of mice (2 ChR2, 1 uninjected control, and 1 EYFP control) was trained to lick for no-odor (blank) trials (and refrain from licking to any odorants presented). The go/no-go odor paradigm (Phase IV) was modified such that mice discriminated rewarded blank trials $\left(\mathrm{S}^{+}\right)$from nonrewarded odorant trials $\left(\mathrm{S}^{-}\right)$by licking the lick spout in response to the $\mathrm{S}^{+}$and refraining from licking to the $\mathrm{S}^{-}$. The "Optogenetic stimulation in odor trials" paradigm was modified so that AON photostimulation was coupled to a subpopulation of $\mathrm{S}^{-}$odor trials. Licking to photostimulation trials would have been rewarded.

\section{Extracellular recordings and optical stimulation}

MTC unit recordings and optical OB stimulation were performed as described previously with several modifications (Rothermel et al., 2014). Briefly, mice were anesthetized with pentobarbital $(50 \mathrm{mg} / \mathrm{kg})$ and placed in a stereotaxic device. A heating blanket (Stryker, T/pump Professional) was used to maintain body temperature at $\sim 37^{\circ} \mathrm{C}$ during the experiment. A local anesthetic (bupivacaine, 1\%; Sigma Millipore) was injected at every incision site. Mice were double tracheotomized, and an artificial inhalation paradigm was used to control air and odorant inhalation independent of respiration (Wachowiak and Cohen, 2001; Spors et al., 2006; Eiting and Wachowiak, 2018). Extracellular recordings were obtained from $\mathrm{OB}$ units using 16-channel electrodes (NeuroNexus, A1x16-5mm50-413-A16, Atlas Neuro, EXVI+R-100-S1-L6 NT) and an RZ5 digital acquisition system (Tucker Davis Technologies). Recordings from presumptive MTCs were obtained from the OB in a depth between 200 and $800 \mu \mathrm{m}$ (measured from electrode tip) and selected as described by Carey and Wachowiak (2011); that is, selected units had to be well isolated and located in the vicinity of the mitral cell layer. Electrode depth was monitored with a digital micromanipulator (Sutter Instruments, MP-225, or Thorlabs PT1/M-Z8). Recording sites were confined to the dorsal OB. Odorant alone ("baseline") and odorant plus optical stimulation trials (at least three trials each) were interleaved for all odorants (interstimulus interval 70s). Recordings with at least 5 repeated trials of each condition were subject to unit-by-unit statistical analysis as described below.

For optical OB stimulation, light was presented as a single $10 \mathrm{~s}$ pulse either alone or simultaneous with odorant presentation using a $470 \mathrm{~nm}$ LED and controller (LEDD1B, Thorlabs) and a $1 \mathrm{~mm}$ optical fiber positioned within $3 \mathrm{~mm}$ of the dorsal OB surface. The light power at the tip of the fiber was between 1 and $10 \mathrm{~mW}$. 
Electrophysiological data analysis

Basic processing and analysis of extracellular data followed protocols previously described for multichannel MTC recordings (Rothermel et al., 2014). Briefly, action potential waveforms with a signal-to-noise ratio of at least 4 SDs above baseline noise were thresholded and saved to disk. Offline sorting was done using the Bayesian clustering algorithm of a spike sorting software (OpenSorter, Tucker Davis Technologies) (see Fig. 6A). "Single units" typically fell within discrete clusters in a space made up of principal components 1 and 2, and units with interspike intervals lower than the absolute refractory period $(<2.5 \mathrm{~ms})$ were excluded from further analysis (Lewicki, 1998) (see Fig. 6B). For units to be classified as presumptive MTCs, units additionally had to be located in the vicinity of the mitral cell layer and display clear sniff modulation (the maximum spike rate in a $100 \mathrm{~ms}$ bin had to be at least 2 times the minimum spike rate for the peristimulus time histogram; see Fig. $6 B$, insets); similar as described by Carey and Wachowiak (2011). Oversampling, the emergence of similar responses on more than one channel, was rarely observed, probably because of the spacing $(>50 \mu \mathrm{m})$ of the individual recording sites. Responses to optical or odorant stimulation were analyzed differently depending on the experimental paradigm: stimulation effects on spontaneous spike rate (no artificial inhalation, "no-sniff" condition) were measured by calculating spikes/s $(\mathrm{Hz})$ for the $9 \mathrm{~s}$ before or during stimulation. Selection of "sniff-modulated" units was performed as described previously (Rothermel et al., 2014). Inhalation-evoked responses during inhalation of clean air ("sniff" condition) were measured by averaging the number of spikes per $1 \mathrm{~s}$ period following each inhalation in the 9 inhalations before stimulation or during stimulation and across multiple trials (minimum of 3 trials in each condition for all units). Odorant-evoked responses were measured as changes in the mean number of spikes evoked per $1 \mathrm{~s}$ inhalation cycle ( $\Delta$ spikes/sniff) during odorant presentation, relative to the same number of inhalations just before odorant presentation. For statistical analysis, significance for changes in firing rate (baseline vs optical stimulation) was tested on a unit-by-unit basis using the MannWhitney $U$ test on units tested with $\geq 5$ trials per condition.

\section{$O B$ electrophysiological recordings in awake mice}

We used a custom-built chronically implanted multitetrode array (MTA) for OB recordings in awake mice with up to 32 channels, adapted from guidelines kindly provided by the laboratory of Wolfgang Kelsch (Oettl et al., 2019). Printed circuit boards were designed to accommodate 8 tetrodes in the OB and a fiber cable for optical AON stimulation (see Fig. 8A). Virus injection, optic fiber, MTA, and head-bar implantation were performed in a single surgical procedure. Mice were accustomed to running on a Styrofoam ball, and recordings started $\sim 3$ weeks after the surgery. Similar protocols as described above were used for extracellular recordings/optical stimulation $(20 \mathrm{~Hz} 25 \mathrm{~ms}$ pulses, $4 \mathrm{~s}$; in some sessions, $4 \mathrm{~s}$ continuous stimulation) and electrophysiological data analysis.

\section{Histology}

Viral (AAV.FLEX.ChR2.YFP, AAV.FLEX.EYPF, and AAV.FLEX. GCaMP6s) expression in AON cells/axonal projections and optic fiber placement were evaluated with post hoc histology in all experiments to confirm accurate targeting of AON neurons and a lack of expression in OB neurons as described previously (Wachowiak et al., 2013; Rothermel et al., 2014). Briefly, mice were deeply anesthetized with an overdose of sodium pentobarbital and perfused with $4 \%$ PFA in PBS. Postfixation was done in 4\% PFA for at least $1 \mathrm{~d}$ before the brains were extracted and later embedded in 3\% low-melting-point agarose. Coronal sections at $200 \mu \mathrm{m}$ thickness were made using a vibratome (752/M vibroslice; Campden Instruments). Slices were evaluated from native fluorescence without immunohistochemical amplification with a TCS SP2 confocal laser scanning microscope (Leica Microsystems) at $10 \times$ or $20 \times$ magnification.

For immunohistochemistry, AON-injected (AAV.FLEX. GCaMP6s) animals were perfused as described above. Brains were cryoprotected in $30 \%$ sucrose in PBS followed by embedding in optimal cutting temperature compound (Tissue Freezing Medium, Leica Microsystems). Coronal slices $(10-14 \mu \mathrm{m})$ were cut on a cryostat (CM 3050S, Leica
Microsystems). Slices were first rinsed with PBS, and nonspecific binding was blocked with $10 \%$ normal goat serum diluted in PBS with $0.2 \%$ Triton X-100 for $1 \mathrm{~h}$ at room temperature before incubation with primary antibody (rabbit anti-GAD65 + GAD67 antibody [ab11070] 1:100 and rabbit anti-CaMKII antibody [ab134041] 1:100, Abcam) in PBS with $0.02 \%$ Triton- $\mathrm{X}$ overnight at $4^{\circ} \mathrm{C}$. As a secondary antibody, goat antirabbit AlexaFluor-546 (Invitrogen) was used. The secondary antibody was incubated for $1 \mathrm{~h}$ at room temperature before labeling was evaluated as reported above. Colocalization of protein was quantified in ImageJ by counting cells from confocal images (CAMKII: three images from two mice; GAD: four images from two mice) from representative sections at bregma $\sim 2.8$ in each animal.

\section{Statistical analysis}

Significance was determined using the paired Student's $t$ test, Wilcoxon signed rank test, Mann-Whitney $U$ test, and Kruskal-Wallis test, where appropriate. Multiple comparison tests were used for post hoc comparisons.

\section{Results}

We used a mouse line in which an IRES-Cre bicistronic cassette was introduced into the $3^{\prime}$ noncoding region of the cholinergic nicotinic receptor $\alpha 7$ gene (Chrna7) by homologous recombination (Rogers et al., 2012b). These mice show robust Cre-dependent expression in cells of the AON in accordance with publications showing strong Chrna7 expression in AON neurons (Dominguez del Toro et al., 1994; Brunjes et al., 2005). Importantly, cellular Cre expression at the level of the $\mathrm{OB}$ is sparse, allowing for a selective labeling of $\mathrm{AON}$ neurons without the potential confound of tracing $\mathrm{OB}$ cells via retrograde AAV transport (Rothermel et al., 2013). Chrna7-cre mice have been used previously to drive GCaMP expression in the AON (Rothermel and Wachowiak, 2014), with labeled cells showing morphologies reminiscent of principal neurons with descending projections to the OB (Brunjes and Kenerson, 2010). To gain a better understanding of the distribution and nature of the Cre-positive cells in the AON, we injected Chrna7-cre mice with an AAV-GCAMP construct ( $n=11$ mice). The bright cytosolic GCaMP expression allowed us to quantify the number of infected cells in different $\mathrm{AON}$ regions (Fig. 1A; pars dorsalis, pars lateralis, pars medialis, and pars ventroposterior, according to Kay and Brunjes, 2014) as well as around the injection tract $(16,466$ cells counted). There was no significant difference in the amount of labeled cells in the AON subregions (pars dorsalis $638 \pm 328$ [mean $\pm \mathrm{SD}$ ] cells $/ \mathrm{mm}^{2}$, pars lateralis $613 \pm 366$ cells $/ \mathrm{mm}^{2}$, pars medialis $303 \pm 331 \mathrm{cells} / \mathrm{mm}^{2}$, pars ventroposterior $404 \pm 285$ cells $/ \mathrm{mm}^{2}$ ). The injection tract in the medial prefrontal cortex (mPFC) displayed significantly less injected cells and therefore renders a contribution of those cells to the observed effects unlikely $\left(20 \pm 10\right.$ cells $/ \mathrm{mm}^{2}, p=1.9 \times 10^{-5}$, Kruskal-Wallis test, nonpaired post hoc test). We also performed immunostainings with antibodies for glutamate decarboxylase (GAD65 + GAD67) as a marker of GABAergic inhibitory interneurons and $\mathrm{Ca}^{2+} /$ calmodulin-dependent protein kinase II (CaMKII), which has been described as marker for AON principle neurons (Esquivelzeta Rabell et al., 2017; Libbrecht et al., 2018) (Fig. 1B). GCaMP-positive cells were only rarely colabeled with GAD antibodies (5.7 $\pm 2.6 \%, n=2$ mice), but we found that a considerable number of GCaMP-positive cells were also positive for CAMKII ( $58.4 \pm 2.6 \%, n=2$ mice). In conclusion, labeled cell bodies could be found in all AON areas, and most of these neurons show markers of AON principle cells.

To target cortical top-down projections from the AON to the OB, we injected AAV.FLEX.ChR2.EYFP into AON of Chrna7cre mice. Viral injection resulted in a ChR2-EYFP expression in 
A
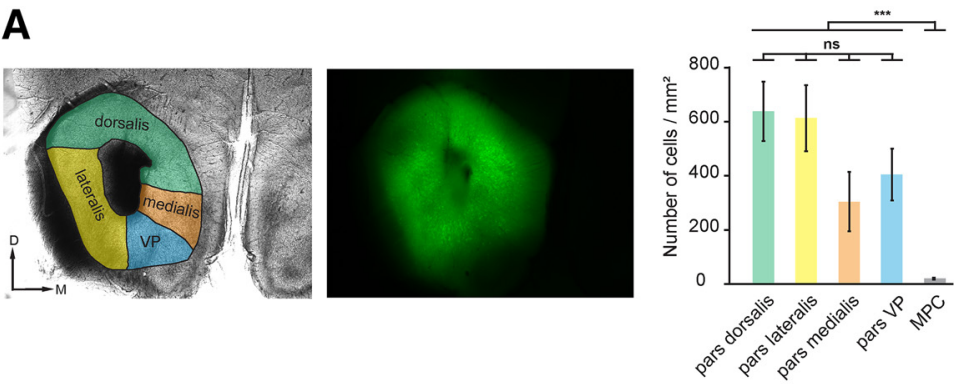

B

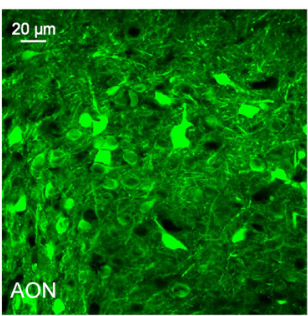

Alpha7-cre/AAV GCaMP6

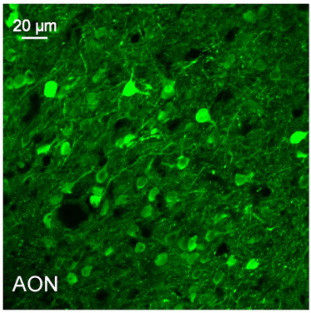

C Alpha7-cre/AAV-ChR2
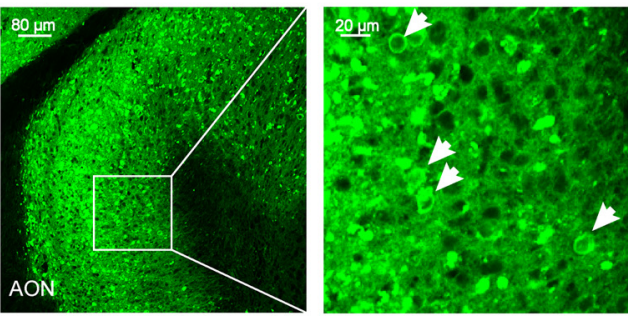

D
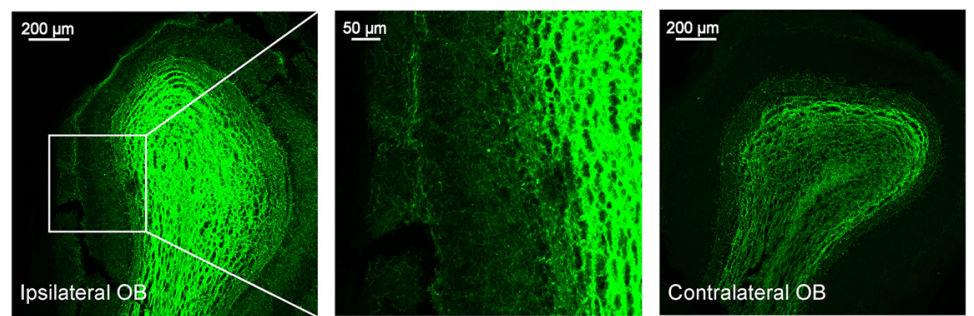

Figure 1. Viral-mediated transgene expression in the AON of Chrna7-Cre mice. $A$, Left, Low-resolution image depicting the left AON of a Chrna7-Cre mouse (2.6 bregma, coronal section). Colored regions represent AON pars principalis subdivisions according to Kay and Brunjes (2014). Middle, Fluorescence image of the same region showing marker protein expression after stereotaxic injection. In this experiment, AAV-GCAMP was injected into AON to better visualize cell bodies. Right, Quantification of the distribution of GCaMP6-positive cells in the different AON subdivisions, including the injection tract in the $\mathrm{mPFC}$. Error bars indicate SEM. There was no significant difference in the amount of labeled cells in the AON subregions. Pars VP, Pars ventroposterior. B, Immunohistochemical staining of AON sections of Chrna7-Cre mice injected with AAV-GCaMP6. Top row, Images represent GCaMP6 expression (green, left), antibody labeling for CaMK II (red, middle), and overlay of both channels (right). Bottom row, Images represent GCaMP6 expression (green, left), antibody labeling for GAD65 + GAD67 (red, middle), and overlay of both channels (right). Arrows indicate examples of dually labeled cells. $C$, AON section of a Chrna7-Cre mouse unilaterally injected with AAV-ChR2-EYFP. Left, Low-magnification confocal image showing AON ChR2-EYFP expression (2.73 bregma; coronal section). Right, Magnification of AON region showing strong cellular ChR2-EYFP expression. White arrows indicate labeled cell somata. D, Left, ChR2-EYFP-expressing AON fibers in the ipsilateral OB following AON AAV-ChR2-EYFP injection in a Chrna7-Cre mouse. ChR2-EYFP-labeled AON axon terminals all major AON subdivisions (pars principalis, dorsal, lateral, medial, and ventral part; including pars externa) similar to AAV. FLEX. GCaMP6s injections (Fig. 1C). Four weeks following unilateral virus infection, ChR2-EYFP protein was apparent in AON fibers throughout the OB (Fig. 1D): ipsilateral AON axon terminals targeted mainly the granule cell layer and, to a lesser extent, the external plexiform layer, whereas fewer fibers in the contralateral external plexiform layer could be observed (Fig. $1 D$, right), consistent with earlier reports (Reyher et al., 1988; Rothermel and Wachowiak, 2014). Based on these results, we conclude that our viral approach mainly labels $\mathrm{AON}$ pars principalis neurons reported to have bilateral $\mathrm{OB}$ projections.

\section{Activation of AON neurons in awake animals is not perceived as an odorant equivalent cue}

To explore possible behavioral effects of AON activation on odorant perception, we initially asked whether photostimulation of ChR2-expressing neurons in the AON could serve as an odorant equivalent cue. The AON as a sensory olfactory cortical area receives direct MTC input from the OB. Since optogenetically induced "illusory" sensory perception has been reported for different sensory areas (O'Connor et al., 2013; Guo et al., 2015), we tested whether AON activation might be able to evoke odor sensations in mice. We used a go/no-go odor discrimination assay in which water-restricted head-fixed mice freely running on a Styrofoam ball (see Materials and Methods) were exposed to different odors $\left(\mathrm{S}^{+}\right)$, all of which were rewarded (Fig. $2 B$ ). In each behavioral session, 4-8 odorants were randomly picked of a repertoire of 36 odorants, so that over time, each mouse encountered all odorants. Within the session, the selected odorants were applied in random order (50-210 trials $\left[\mathrm{S}^{+}\right.$and $\mathrm{S}^{-}$presentations] per session; 30-90 min duration). $\mathrm{S}^{+} / \mathrm{S}^{-}$presentation was also randomized (50/50 distribution). During this period, mice learned to lick to any given odor stimulus and to refrain from licking to clean air ( $\mathrm{S}^{-}$, blank trial). When mice performed reliably above criterion ( $>80 \%$ accuracy; odor hits + correct rejections/number of trials; see Materials and Methods), we tested whether unilateral photostimulation of ChR2-expressing $\mathrm{AON}$

targeted primarily the granule cell layer $(\mathrm{GCL})$ and the external plexiform layer. Middle, Magnified view showing abundant axonal projections. Right, Confocal image from the contralateral $\mathrm{OB}$ displaying $\mathrm{AON}$ terminals predominantly in the $\mathrm{GCL}$. ${ }^{* * *} p<0.0005$, ns, not significant. 
A
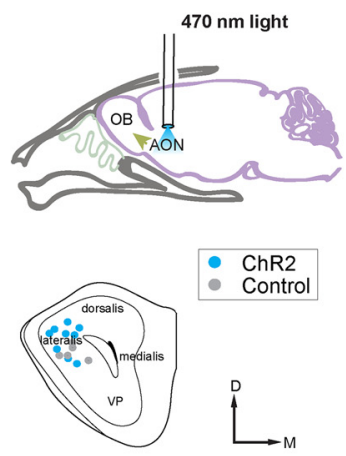

B

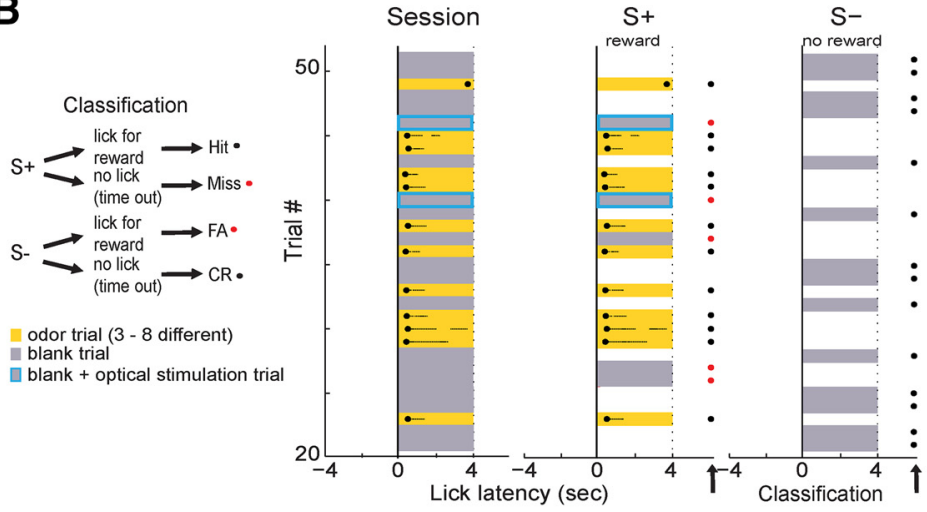

C

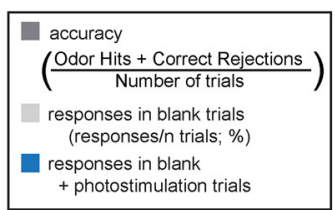

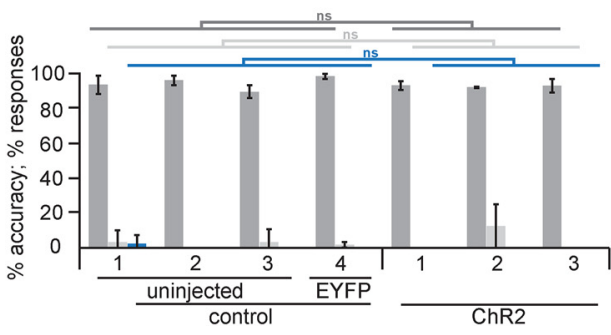

D

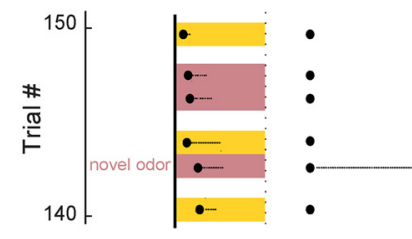

Figure 2. Optogenetic AON activation is not perceived as an odorant equivalent cue. $A$, Top, Schematic of experimental approach. Bottom, Overview of optical fiber tip locations within the AON of ChR2 (blue) and control (gray) mice. D, Dorsal; M, medial. $\boldsymbol{B}$, Representative part of one behavioral session (left, ordinate displays trial number in chronological order). Mice were trained in a go/no-go odor paradigm and discriminated rewarded odorants ( $S^{+}$, yellow squares, odor duration $\left.4 \mathrm{~s}\right)$ from clean air $\left(S^{-}\right.$, "blank," gray squares) by licking in response to the $S^{+}$and refraining from licking to the $S^{-}$. Three to eight odorants (randomly picked out of a repertoire of 36 total odorants) were applied in random order. For simplification, yellow squares represent all odorants in this session. Middle, Right, Behavioral session subtrials ordered by $\mathrm{S}^{+}$(middle) and $\mathrm{S}^{-}$(right) trials. Solid black dot represents first licks in each trial. Light dots represent subsequent licks. Each trial is categorized according to the classification depicted on the left. Briefly, a response on a $S^{+}$trial (hit) and no response during an $S^{-}$trial (correct rejection) were categorized as correct responses (black dots at the end of the odor presentation); no response on a $S^{+}$trial (miss) or a response during an $S^{-}$trial (false alarm) was categorized as incorrect responses (red dots at the end of the odor presentation). Approximately $10 \%$ of $S^{+}$trials consisted of a blank presentation, and licking to these trials would have been rewarded. Blue box represents blank + AON photostimulation trials (in $\mathrm{S}^{+}$condition). Mice did not lick to $\mathrm{S}^{+}$blank or $\mathrm{S}^{+}$blank + photostimulation trials. C, Odor response accuracy and \% responses in blank and blank + photostimulation trials for control and ChR2 animals. No significant difference was observed within and between individual ChR2 or control mice ( $n=7$ mice, 32 sessions). D, Part of a representative "Novel odor trial" session. Pink represents the novel odorant. Yellow represents "familiar" odorants. The animal responded to the novel odorant in the first trial. No difference in licking response to novel or familiar odorants was observed. ns, not significant.

neurons would elicit licking responses when applied without sensory input (3 ChR2, 3 uninjected controls and 1 EYFP control, 32 sessions). Therefore, we modified the behavioral paradigm such that, in $\sim 10 \%$ of $\mathrm{S}^{+}$trials, we presented a blank (clean air) instead of an odorant (gray bars in the $\mathrm{S}^{+}$condition; Fig. $2 B$ ) and licking to these trials would have been rewarded. As expected, mice did not lick to $\mathrm{S}^{+}$blank trials (Fig. $2 B, C$ ). When we coupled the $\mathrm{AON}$ photostimulation to a subpopulation of $\mathrm{S}^{+}$blank trials (gray bars with blue surrounding), mice equally failed to respond, suggesting that activating $\mathrm{AON}$ was not able to elicit an odor percept. In order to ask whether AON activation might trigger odor perception, this low number of optogenetic stimulation trials was necessary as mice had to stay trained to associate water reward with real odor presentation. Importantly, mice were not trained to report to optogenetic stimulation since it has been shown that with a sufficiently high trial number ( $\geq 650$ stimulations) animals can be trained to report essentially any kind of rewarded stimulus in any brain area, for example, from optogenetic stimulation of one OB glomerulus (Smear et al., 2013) to electrical activation of single cells (Histed et al., 2013). Lick responses in blank trials did not differ significantly from responses in blank + photostimulation trials within and between individual ChR2 or control animals (Fig. 2C; \% blank responses $2.11 \pm 0.79$ control, $4.17 \pm 4.17$ ChR2; \% blank + photostimulation responses
$0.63 \pm 0.63$ control, 0 ChR2; $p=0.29$, Kruskal-Wallis test). We performed the experiments using four different optogenetic pulse protocols. The absence of a licking response in the photostimulation trials is unlikely to be caused by a lack of motivation as general performance accuracy (odor hits + correct rejections/number of trials) was high in all mice, and smaller differences in accuracy levels were not significant within and between individual $\mathrm{ChR} 2$ and control mice (94.56 $\pm 1.89 \%$ control, $92.9 \pm 0.34 \%$ ChR2 [mean \pm SEM]; $p=0.09$, Kruskal-Wallis test). Mice also failed to respond to AON stimulation when this paradigm was repeated for 6 consecutive days, showing that mice did not report optogenetic stimulation with this amount of trials.

Likewise, the lack of lick responses in blank + photostimulation trials was not because of a failure to generalize for odorants since both ChR2-expressing ( 4 animals, 10 sessions) and control mice (3 uninjected animals, 6 sessions) directly licked to any not previously encountered odor (Fig. 2D).

To exclude the possibility that the lack of lick responses in blank + photostimulation trials was because of the unilateral AON stimulation, which might be perceived differently compared with bilaterally sampled $\mathrm{S}^{+}$odorants, we also performed bilateral AON stimulations in a separate cohort of animals (2 ChR2 mice and 1 EYFP control mouse, 18 sessions; see Fig. 4). As with unilateral stimulation, no significant differences between 
A

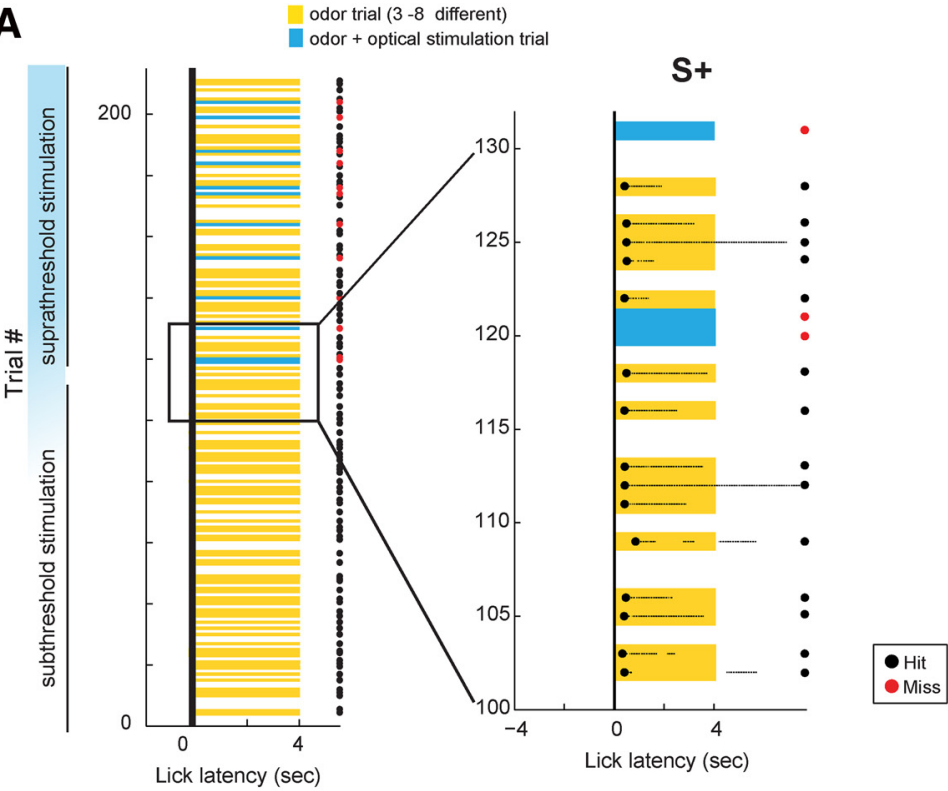

B

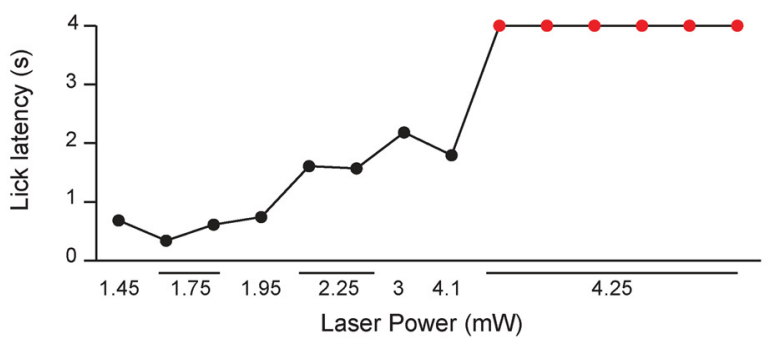

C

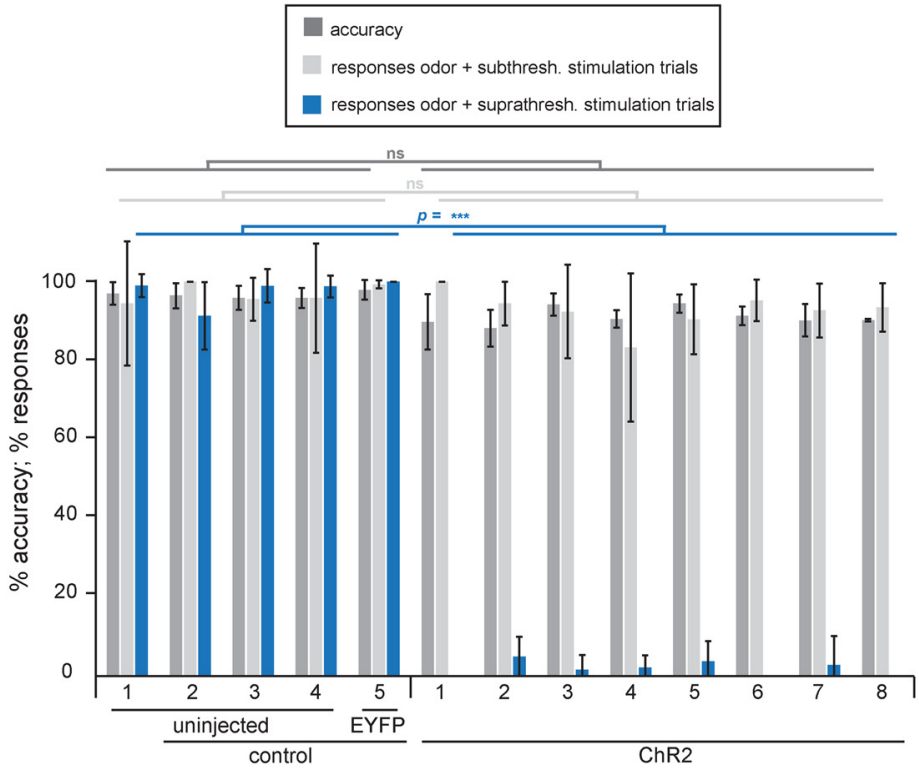

Figure 3. Optogenetic AON activation suppresses odorant detection. A, Representative go/no-go behavioral session. Mice were trained in a go/no-go odor paradigm and discriminated rewarded odorants $\left(S^{+}\right.$, yellow squares, odor duration $\left.4 \mathrm{~s}\right)$ from clean air ( $S^{-}$, "blank," gray squares) by licking in response to the $S^{+}$and refraining from licking to the $S^{-}$. Three to eight odorants (randomly picked out of a repertoire of 36 total odorants) were applied in random order. For simplification, yellow squares represent all odorants in this session. One odor was chosen, and AON photostimulation was coapplied with that particular odor ( $4 \mathrm{~s}$ duration, starting simultaneously). Selected odors changed between sessions. Optical stimulation trials were randomly interspersed with trials with no stimulation $\left(\mathrm{S}^{+}\right.$and $\left.\mathrm{S}^{-}\right)$. Photostimulation intensity was gradually increased from trial to trial (range 1-10 mW). Unless noted otherwise, all photostimulation trials before odor suppression are categorized as subthreshold stimulations (blue represents suprathreshold trials). Lick responses are only depicted in the magnification on the right. AON photostimulation strongly suppresses odorant detection. $\boldsymbol{B}$, Lick latency (s) plotted as a function responses in blank trials and responses in blank + photostimulation trials could be observed (\% blank responses $1.78 \pm 1.67$ control, $4.34 \pm 1.21$ ChR2; \% blank + photostimulation responses $3.33 \pm 3.16$ control, $2.1 \pm 2.08$ ChR2; $p=0.81$, KruskalWallis test). General performance accuracy was high and not significantly different within and between ChR2-expressing and control mice (95.89 $\pm 1.14 \%$ control, $93.79 \pm 0.67 \%$ ChR2 [mean $\pm \mathrm{SEM}$ ]; $p=0.65$, Kruskal-Wallis test).

In conclusion, our data suggest that AON activation does not seem to trigger odor perception.

\section{AON activation impairs odor detection in awake behaving animals}

Next, we asked whether photostimulation of ChR2-expressing neurons in the AON might affect behavioral odor responses. Experiments were partially conducted in the same animal cohort used for the previous behavioral experiments. A similar go/no-go odor discrimination assay was used in which mice were trained to lick to different odors $\left(\mathrm{S}^{+}\right)$and refrain from licking to clean air $\left(\mathrm{S}^{-}\right)$. Each behavioral session consisted of an initial baseline session (duration range from 10 to $30 \mathrm{~min}$; 20-100 trials) in which the mouse's response to different odors $\left(\mathrm{S}^{+}\right)$and clean air $\left(\mathrm{S}^{-}\right)$was determined. Both experimental groups (ChR2-injected and control animals) performed reliably above criterion (80\% accuracy). Following this baseline period, one odor was randomly chosen and AON photostimulation was coapplied with that odor (Fig. 3A; 4s duration, starting simultaneously; $20 \mathrm{~Hz}$ with $25 \mathrm{~ms}$ pulses, for 4s), adopted from Choi et al. (2011). Odor + AON stimulation trials were interleaved with $\mathrm{S}^{-}$and odor only trials (Fig. 3A; 8 ChR2, 4 uninjected controls, and 1 EYFP control, 126 sessions). During this period, the photostimulation intensity was gradually increased (range 1-10 $\mathrm{mW}$ ). Plotting lick latency as a function of laser power (Fig. 3B) revealed a photostimulation power-dependent increase in lick latency $(0.51 \pm 0.03$ to $1.5 \pm 0.31 \mathrm{~s}$; photostimulated

$\leftarrow$

of laser power (mW). Increased laser power led first to an increase in lick latency before causing complete suppression of odorant-evoked licking. C, Odor response accuracy and \% responses during subthreshold/suprathreshold odor + photostimulation trials for control and ChR2 animals. Suprathreshold stimulation selectively suppresses odorant detection in all tested ChR2 mice. There was no difference in task accuracy and \% responses in subthreshold trials within and between control and ChR2 mice ( $n=13$ mice, 126 sessions). ${ }^{* *} p<0.0005$, ns, not significant. 


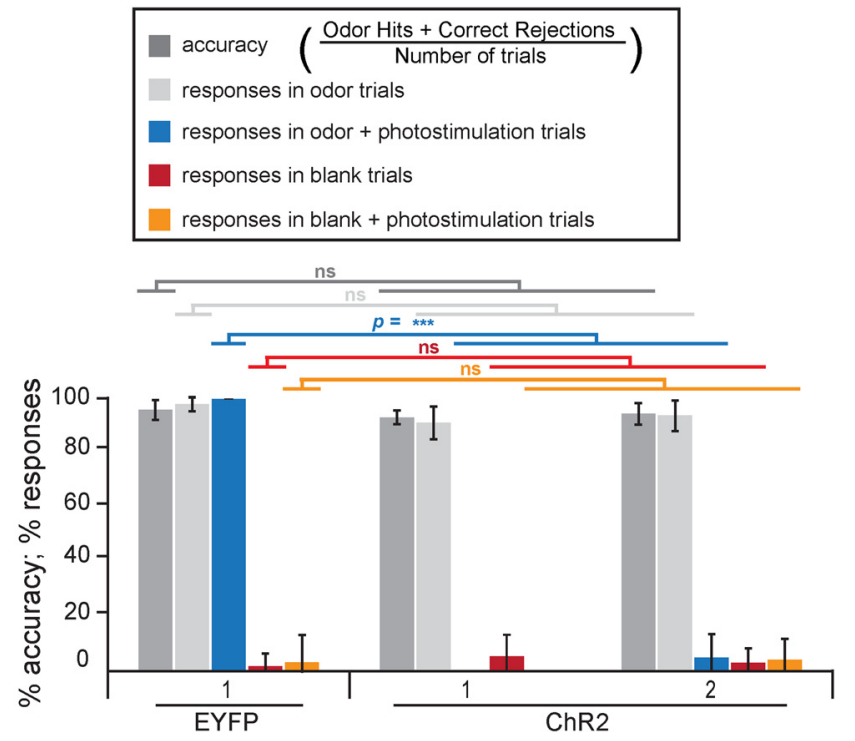

Figure 4. Bilateral AON photostimulation in odor and blank trials. Odor response accuracy and \% responses in odor, odor + photostimulation, blank, as well as blank + photostimulation trials for EYFP control and ChR2 mice (suprathreshold photostimulation; same laser intensity in odorant and blank trials). No significant differences between responses in blank trials and responses in blank + photostimulation trials could be observed. Photostimulation in odor trials, however, suppressed odorant detection in all tested ChR2 mice. Task accuracy and \% responses in odor/blank trials within and between EYFP control and ChR2 mice were not statistically different ( $n=3$ mice, 18 sessions). ${ }^{* * *} p<0.0005$, ns, not significant.

odor, $p=0.03$, Wilcoxon signed rank test) that was restricted to the odor coupled to photostimulation in the ChR2 group $(0.46 \pm 0.02$ to $0.56 \pm 0.11 \mathrm{~s}$; nonphotostimulated odors, $p=0.36$, Wilcoxon signed rank test). A further slight increase in photostimulation intensity caused a failure of licking responses $(0.51 \pm 0.03$ to $4 \mathrm{~s}$ [licktimeout]; photostimulated odor, $p=0.03$, Wilcoxon signed rank test) of only that particular odor coupled to light stimulation $(0.46 \pm 0.02$ to $0.58 \pm 0.1 \mathrm{~s}$; nonphotostimulated odors, $p=0.46$, Wilcoxon signed rank test; Fig. $3 B)$. This effect was not observed in control animals $(0.45 \pm 0.01$ to $0.43 \pm 0.02 \mathrm{~s}$; photostimulated odor, $p=0.44 ; 0.45 \pm 0.02$ to $0.45 \pm 0.01 \mathrm{~s}$; nonphotostimulated odors, $p=0.9$, Wilcoxon signed rank test). "Suprathreshold" photostimulation significantly inhibited responses to odor presentation (measured in percentage of the total number of trials in this condition) in all ChR2 mice compared with control animals (Fig. 3C, blue bars; 97.59 $\pm 1.58 \%$ control, $1.93 \pm 0.66 \%$ ChR2 [mean $\pm \mathrm{SEM}] ; p=5 \times 10^{-10}$, Kruskal-Wallis test, nonpaired post hoc test). The reduction of a licking response in these "suprathreshold" photostimulation trials was unlikely to be the result of a declining motivation as general performance accuracy as well as the percentage of responses during odor presentation in subthreshold stimulation trials did not differ significantly within and between ChR2 and control mice (Fig. 3C, dark and light gray bars; accuracy: $96.61 \pm 0.37 \%$ control, $91.1 \pm 0.76 \%$ ChR2; $p=0.08$, subthreshold stimulation: $97.01 \pm 1.1 \%$ control, $92.74 \pm 1.67 \%$ ChR2; $p=0.13$ Kruskal-Wallis test). Additionally, odor presentation without photostimulation led to a normal response in ChR2 mice. Control mice did not show any effects on photostimulation regardless of the applied laser power (range 1-10 $\mathrm{mW}$ ) as did ChR2 mice when trained to a nonolfactory detection task (data not shown), showing that mice could perform well during light stimulation. Inhibition of licking response to odor presentation during "suprathreshold" photostimulation
Table 1. Optogenetic AON activation modulates odorant detection independent of odor identity ${ }^{a}$

\begin{tabular}{|c|c|c|c|c|c|c|c|}
\hline \multirow[b]{2}{*}{ Odor } & \multirow{2}{*}{$\begin{array}{l}\text { No. of } \\
\text { sessions }\end{array}$} & \multicolumn{2}{|l|}{ Control } & \multirow[b]{2}{*}{$p$} & \multicolumn{2}{|l|}{$\mathrm{ChR2}$} & \multirow[b]{2}{*}{$p$} \\
\hline & & Subthreshold & Suprathreshold & & Subthreshold & Suprathreshold & \\
\hline IAA & 23 & 93.52 & 98.56 & NS & 93.43 & 2.00 & $* * *$ \\
\hline MV & 29 & 100.00 & 94.82 & NS & 94.72 & 0.00 & $* * *$ \\
\hline ET & 10 & 91.67 & 100.00 & NS & 94.44 & 0.00 & * \\
\hline PB & 14 & 99.60 & 97.33 & NS & 97.22 & 5.00 & * \\
\hline MH & 15 & 100.00 & 97.27 & NS & 89.32 & 1.79 & $* * *$ \\
\hline $\sec B A$ & 19 & 100.00 & 94.65 & NS & 91.51 & 0.67 & $* * *$ \\
\hline$E B$ & 16 & 100.00 & 96.75 & NS & 92.61 & 0.00 & $* * *$ \\
\hline$M B$ & 12 & 100.00 & 100.00 & NS & 90.29 & 2.22 & $* *$ \\
\hline 2-Нер & 13 & 99.24 & 94.84 & NS & 94.45 & 0.00 & $* * *$ \\
\hline 2-Hex & 10 & 90.28 & 98.72 & NS & 95.00 & 0.00 & * \\
\hline VB & 9 & 95.05 & 100.00 & NS & 94.33 & 6.25 & * \\
\hline 2-Pen & 17 & 100.00 & 100.00 & NS & 92.51 & 2.38 & $* * *$ \\
\hline Mix4 & 11 & 95.42 & 98.57 & NS & 98.75 & 0.00 & $*$ \\
\hline Total & 198 & & & & & & \\
\hline
\end{tabular}

$\overline{{ }^{a} \text { AON photostimulation was coapplied with different odorants within one session. Photostimulation signifi- }}$ cantly reduces licking responses in suprathreshold trials across all tested odorants (12 monomolecular odorants, one mixture of 4 odorants) in (hR2 mice (8 animals, 97 sessions). No significant difference in performance between subthreshold and suprathreshold trials was observed in control animals (4 animals, 101 sessions).

${ }^{*} p<0.05 ;{ }^{* *} p<0.005 ;{ }^{* * *} p<0.0005$

trials was also observed in bilaterally stimulated mice (Fig. 4; 100\% control, $2.5 \pm 2.05 \%$ ChR2 [mean \pm SEM]; $p=1.25 \times 10^{-9}$, Kruskal-Wallis test, nonpaired post hoc test).

We also tested whether AON photostimulation is able to suppress responses to different odorants. Therefore, in separated sessions, different odorants were coupled to the photostimulation. Licking responses could not only be inhibited by AON photostimulation for all tested monomolecular odorants but also for an odor mixture (Table 1; 8 ChR2 animals, 97 sessions, 12 monomolecular odorants, one mixture of 4 odorants; each odorant was tested in at least 4 sessions). In sessions where we switched optogenetic stimulation rapidly between up to 6 odorants, we were able to demonstrate that licking to all stimulation coupled odorants could be inhibited, even within a single behavior session (Fig. 5A). This demonstrates that (1) AON-mediated inhibition of odor responses is not odor-specific; (2) the AON inhibits odor responses on a fast timescale; and (3) there is no training effect involved. As shown previously, animals were able to generalize to a novel odor stimulus (Fig. 2D), which renders it unlikely that the absence of licking in odor + photostimulation trials is caused by an AON-mediated change in/or novel odor percept. Photostimulation in control animals had no significant effect on odor responses (Table 1; 4 controls, 101 sessions, 12 monomolecular odorants, one mixture of 4 odorants). We also examined whether the effect of AON activation could be overcome by stronger sensory input. For this, we set the laser strength to the minimal light intensity necessary for inhibiting odor detection at a concentration of $0.5 \%$ (saturated vapor pressure). Odor concentration was then gradually increased from $0.5 \%$ to $4.5 \%$ (Fig. $5 B)$. AON photostimulation significantly inhibited odor detection over this whole concentration range (lick delay [seconds, mean $\pm \mathrm{SD}$ ] of ChR2 mice [ 4 animals, 40 sessions] vs photostimulated controls [ 3 animals, 53 sessions]; $4 \mathrm{~s}=$ no lick, $0.1 \%$, $4 \pm 0 \mathrm{~s}$ vs $0.52 \pm 0.05 \mathrm{~s}, p=5.8 \times 10^{-4} ; 0.5 \%, 3.97 \pm 0.06 \mathrm{~s}$ vs $0.58 \pm 0.57 \mathrm{~s}, p=2.5 \times 10^{-4} ; 1 \%, 4 \pm 0 \mathrm{~s}$ vs $0.83 \pm 0.91 \mathrm{~s}, p=1 \times$ $10^{-4} ; 2 \%, 4 \pm 0 \mathrm{~s}$ vs $0.4 \pm 0.08 \mathrm{~s}, p=4.6 \times 10^{-5} ; 3 \%, 4 \pm 0 \mathrm{~s}$ vs $0.4 \pm 0.05 \mathrm{~s}, p=4.5 \times 10^{-5} ; 4 \%, 3.81 \pm 0.36 \mathrm{~s}$ vs $0.56 \pm 0.32 \mathrm{~s}$, $p=0.009$; Mann-Whitney $U$ test for $\geq 4$ sessions per odorant concentration). 


\section{A odor specificity}

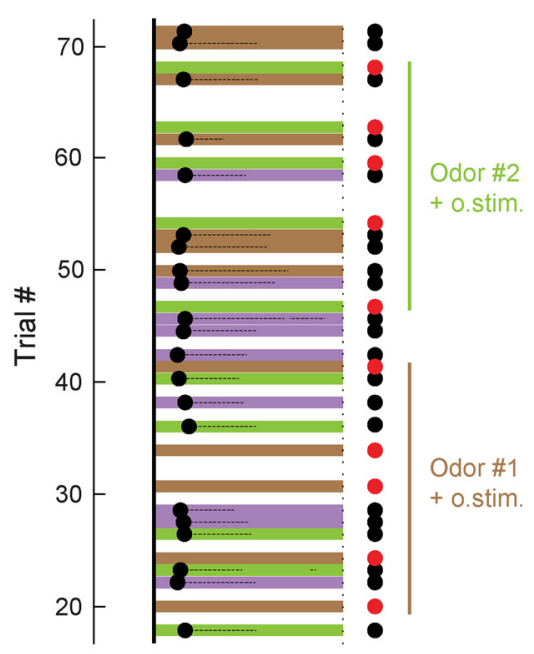

B odor concentration

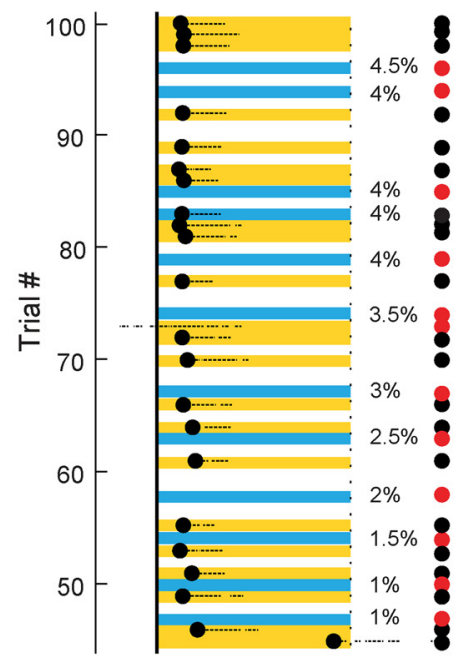

C timing

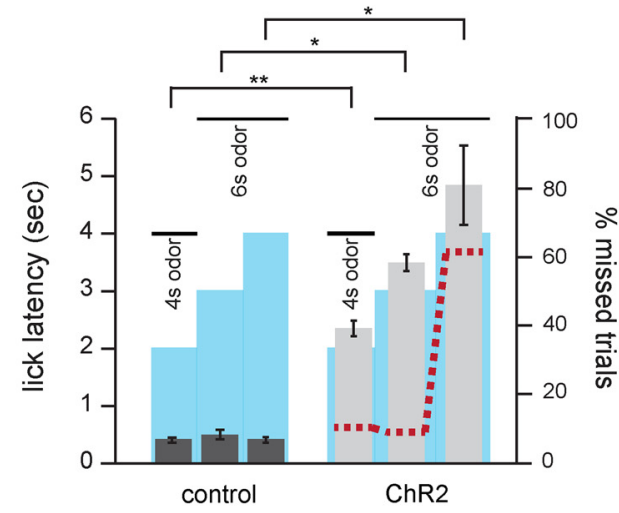

D

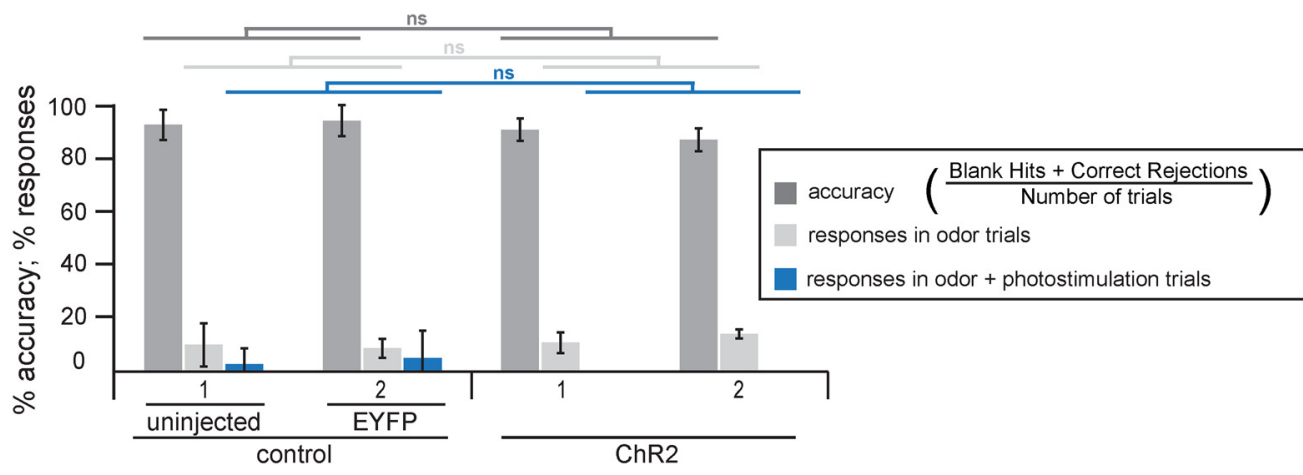

Figure 5. Optogenetic AON activation modulates odorant detection independent of odor identity and concentration. $A$, Lick responses to different odorants could also be inhibited within a single behavior session by quickly switching optical stimulation between odorants. Representative part of one behavioral session showing suppression of odor detection for two different odorants. In contrast to previous plots, individual odorants are color-coded. $\boldsymbol{B}$, AON photostimulation significantly inhibits odor detection over a large concentration range. Representative part of a training session in which odor concentration was gradually increased from $1 \%$ to $4.5 \%$. Suppression of odor detection occurred at all tested concentrations. C, Timing of AON photostimulation affects behavioral responses. Decreasing the photostimulation time relative to the odor duration led to an immediate response (lick latency [s]) at the end of the photostimulation in ChR2 animals. Blue box represents photostimulation duration. Black bar represents odor stimulation length. Longer stimulation times also increased the number of missed trials (red dotted line). $\boldsymbol{D}$, AON photostimulation in $\mathrm{S}^{-}$odor trials. Blank response accuracy and \% responses in odor and odor + photostimulation trials for control and ChR2 mice. Animals trained to report the absence of odorants did not lick in odor + AON stimulation trials. No significant difference was observed within and between individual ChR2 or control mice $(n=4$ mice, 20 sessions). * $p<0.05$. ${ }^{* *} p<0.005$, ns, not significant.

Finally, we investigated the relative timing of AON photostimulation effects on behavioral responses by varying stimulation times from the default settings ( $4 \mathrm{~s}$ both, given simultaneously). Using a paradigm of decreased photostimulation time relative to the odor duration, we found that ChR2 mice ( 3 animals, 12 sessions) immediately licked at the end of the photostimulation: a 2, 3 , and $4 \mathrm{~s}$ optical stimulation, which was followed by several seconds of "unmasked" odor, resulted in a lick delay of $2.38 \pm 0.08$, $3.52 \pm 0.08$, and $4.87 \pm 0.22 \mathrm{~s}$, respectively (Fig. 5 C). Lick delays of ChR2 mice at any photostimulation length were significantly different compared with control mice ( 3 animals, 17 sessions) (lick delay [seconds, mean $\pm \mathrm{SD}$ ] of ChR2 mice vs photostimulated controls; $2 \mathrm{~s}$ photostimulation $2.38 \pm 0.08$ vs $0.42 \pm 0.07 \mathrm{~s}$, $p=0.004 ; 3 \mathrm{~s}$ photostimulation $3.52 \pm 0.08$ vs $0.46 \pm 0.06 \mathrm{~s}, p=$ 0.02 ; $4 \mathrm{~s}$ photostimulation $4.87 \pm 0.22$ vs $0.43 \pm 0.04 \mathrm{~s}, p=0.03$; Mann-Whitney $U$ test). Interestingly, ChR2 mice failed significantly more often to lick in response to $4 \mathrm{~s}$ photostimulation trials compared with shorter stimulation lengths (Fig. 5C; \% missed trials; $2 \mathrm{~s}$ photostimulation $9 \%, 3 \mathrm{~s}$ photostimulation $7 \%, 4 \mathrm{~s}$ photostimulation $61 \% ; p=2.5 \times 10^{-9}$, Kruskal-Wallis test, nonpaired post hoc test). This suggests that longer photostimulation produces longer-lasting effects. In contrast to that, varying the odor length at a fixed photostimulation had no significant effect on lick latency (laser $2 \mathrm{~s}$, lick delay: $2.7 \pm 0.18 \mathrm{~s}$ [4 s odor], $3.07 \pm 0.24 \mathrm{~s}$ [ $6 \mathrm{~s}$ odor], $2.5 \pm 0.11 \mathrm{~s}$ [ $8 \mathrm{~s}$ odor], $p=0.12$, KruskalWallis test; data not shown).

Taken together, we found that, in mice trained to associate water rewards with odorants, optogenetic $\mathrm{AON}$ stimulation alone was not able to elicit a behavioral response. AON stimulation during odor presentation, however, strongly suppressed licking responses.

\section{AON stimulation changes odor perception}

So far, our data rather favor the interpretation of an $\mathrm{AON}$-mediated suppression of odor detection compared with a modulation of odor perception (e.g., intensity, timing). To distinguish between these two possibilities, we trained a separate cohort of animals (2 ChR2 mice, 1 uninjected control, and 1 EYFP control mouse, 20 sessions) to lick to blank stimuli $\left(\mathrm{S}^{+}\right)$while refraining 
to lick to any given odorants $\left(\mathrm{S}^{-}\right)$. After reaching criterion performance, we stimulated the $\mathrm{AON}$ during $\mathrm{S}^{-}$odor presentation (and licking to these trials would have been rewarded): if $\mathrm{AON}$ stimulation completely suppresses odorant perception, odor + AON stimulation should be perceived as clean air and mice should lick. If stimulation alters the perception of the odor, the mice should not lick. We found that mice did not start to lick to odor + photostimulation trials (Fig. 5D). Lick responses in odor trials did not differ significantly from responses in odor + photostimulation trials within and between individual ChR2 or control animals (Fig. 5D; \% odor responses 9.21 \pm 0.6 control, $12.24 \pm 1.62 \mathrm{ChR} 2 ; \%$ odor + photostimulation responses $3.93 \pm$ 1.07 control, 0 ChR2; $p=0.09$, Kruskal-Wallis test). General performance accuracy was high and did not differ significantly within and between individual ChR2 and control mice (91.35 $\pm 0.76 \%$ control, $86.91 \pm 1.85 \%$ ChR2 [mean \pm SEM]; $p=0.19$, KruskalWallis test). Mice also failed to respond to odor + AON stimulation when this paradigm was repeated for 6 consecutive days. These results render it unlikely that mice perceive odor $+\mathrm{AON}$ stimulation as clean air. Instead, AON stimulation might modulate odor perception so profoundly that mice, trained to respond to odors, do not recognize it as a go stimulus anymore.

\section{Optogenetic activation of $\mathrm{AON}$ axons in the $\mathrm{OB}$ has an inhibitory effect on spontaneous and inhalation-evoked MTC spiking}

The observed changes in behavior could be caused by a large number of modulatory changes along the different levels of odor processing since the AON is abundantly connected with olfactory as well as nonolfactory brain centers. We next switched to electrophysiological recordings to elucidate possible mechanisms of AON stimulation-dependent change in odor perception. Because of the dense top-down projections from the AON to the $\mathrm{OB}$, which constitutes the first relay station of olfactory information in the brain, we tested for direct AON-mediated modulation of $\mathrm{OB}$ output activity.

For this, we stimulated AON fibers while recording electrical activity in the $\mathrm{OB}$ of anesthetized mice. Direct stimulation of AON fibers in the OB should prevent interfering effects from other brain areas, whereas the anesthetized preparation offers tight sensory stimulation control. We directed $473 \mathrm{~nm}$ light (at similar power levels used in behavioral experiments; $1-10 \mathrm{~mW}$ total power) onto the dorsal $\mathrm{OB}$ surface while recording multichannel electrical activity from dorsally located presumptive MTCs in anesthetized, double-tracheotomized mice (Fig. 6K) (see Materials and Methods).

First, to assess the impact of AON fiber stimulation on MTC excitability in the absence of sensory input, we optically activated AON axons without ongoing inhalation (Fig. $6 C-E$ ). In the absence of inhalation-derived input, MTCs display irregular firing (Carey and Wachowiak, 2011; Courtiol et al., 2011; Rothermel et al., 2014). Optical stimulation led to a significant reduction in MTC spontaneous spiking from $3.4 \pm 3.68 \mathrm{~Hz}$ (mean \pm SD) before stimulation, to $1.81 \pm 2.45 \mathrm{~Hz}$ during stimulation $(n=51$ units from 8 mice; $p=1.52 \times 10^{-4}$, Wilcoxon signed rank test). Only cells in which the stimulation was repeated $\geq 5$ times were included for analysis. This criterion supports a test of significance on each unit; 21 of these units (41\%) showed a significant stimulation-evoked change in firing activity when tested on a unit-by-unit basis (Mann-Whitney $U$ test). Of these cells, 19 showed a statistically significant reduction in firing rate, and only 2 showed an increase (Fig. 6D). Among these 19 units, the median firing rate decreased by $2.89 \pm 3.06 \mathrm{~Hz}$. In all recorded units, the decrease in spontaneous firing rates persisted for the whole duration of the optical stimulation (10 s). Following the stimulation, an increase in spiking was observed that returned to prestimulus levels within $25 \mathrm{~s}$ after stimulation ceased (Fig. 6C, $E)$. Spiking activity was also reduced when exclusively stimulating $\mathrm{AON}$-derived fibers in the contralateral $\mathrm{OB}$ in unilaterally injected animals ( $n=13$ units from 2 mice; $3.16 \pm 2.31 \mathrm{~Hz}$ before stimulation, $2.16 \pm 2.05 \mathrm{~Hz}$ during stimulation; $p=0.017$, Wilcoxon signed rank test; Fig. $6 D$, inset). In control mice, the same optical stimulation protocol failed to significantly modulate MTC spontaneous spiking ( $n=15$ units from 2 mice; $7.43 \pm 3.51 \mathrm{~Hz}$ before stimulation, $7.51 \pm 3.65$ during stimulation; $p=0.5$, Wilcoxon signed rank test; data not shown). Thus, optogenetic activation of AON fibers leads to a strong reduction of spontaneous spiking of MTCs.

Next, we investigated the effect of AON axon activation on MTC responses during artificial inhalation of clean air. Inhalationlinked spiking patterns could be observed in 85 units from 10 mice, most likely reflecting weak sensory-evoked responses (Grosmaitre et al., 2007; Carey et al., 2009; Rothermel et al., 2014). Optical stimulation of $\mathrm{AON}$ axons strongly diminished inhalation-linked spiking of MTCs (Fig. 6F). However, an initial but fast decaying (within $30 \mathrm{~ms}$ ) excitatory stimulation effect (Fig. 6I), similar to that reported by Markopoulos et al. (2012), could be observed by adjusting the bin size from 100 to $1 \mathrm{~ms}$. Light-induced reduction of spiking activity was highly significant across the population of presumptive MTCs, with median spike rate decreasing from $3.07 \pm 2.4 \mathrm{~Hz}$ to $1.66 \pm 2.39 \mathrm{~Hz}$ during optical stimulation $\left(p=7.45 \times 10^{-11}\right.$, Wilcoxon signed rank test). When tested on a unit-by-unit basis, 54 of 85 recorded units (62.35\%) showed a significant optical stimulation-evoked change in spiking (Fig. 6G); 52 units showed a significant decrease in spikes per sniff. Inhalation-evoked spiking of these 52 cells decreased by $2.2 \pm 1.69 \mathrm{spikes} / \mathrm{sniff} / \mathrm{s}$ (mean $\pm \mathrm{SD}$ ). Only 2 units showed an increase in spikes per sniff. Sniff-triggered spike histograms depicting MTC spiking within the course of one inhalation/ sniff showed that, although $\mathrm{AON}$ axon stimulation in the $\mathrm{OB}$ strongly reduced peak spike rate, it did not alter the temporal pattern of MTC responses relative to inhalation (Fig. 6J); that is, the time bin of peak firing did not change across the population of recorded units $(p=0.16$, paired $t$ test comparing time bin of the peak of inhalation-evoked firing rate for baseline vs optical stimulation). Across the population of all recorded units, the decrease in inhalation-evoked spike rates persisted for the duration of the $10 \mathrm{~s}$ optical stimulation (Fig. $6 \mathrm{H}$ ) and was not significantly different from the reduction in spike rate observed on spontaneous MTC firing (decrease by $1.59 \pm 2.94$ spontaneous MTC spiking condition, $1.41 \pm 1.82$ inhalation evoked spiking condition, $p=0.46$, Mann-Whitney $U$ test). Following stimulation, spike rate increased above baseline levels for $<25 \mathrm{~s}$ before returning to prestimulus levels (Fig. $6 F$, Unit 2, Fig. $6 H$ ). Thus, transient activation of $\mathrm{AON}$ axons in the OB leads to a reduction in inhalation-linked MTC activity without grossly reorganizing temporal patterns of sensory input. This inhibition has a fast onset and persists for the duration of the optical stimulation.

\section{Optogenetic activation of $A O N$ axons in the $\mathrm{OB}$ suppresses odorant-evoked MTC spiking}

Since odor detection was strongly suppressed in our behavioral data, we next evaluated the impact of bulbar AON modulation on odorant responses by comparing MTC odorant responses with and without optogenetic AON activation (Fig. 7A). Across 
A

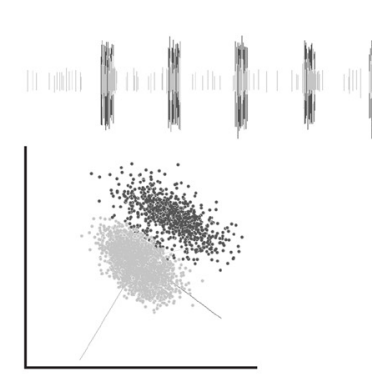

PC 1

$\mathbf{C}_{\text {no sniff }}$

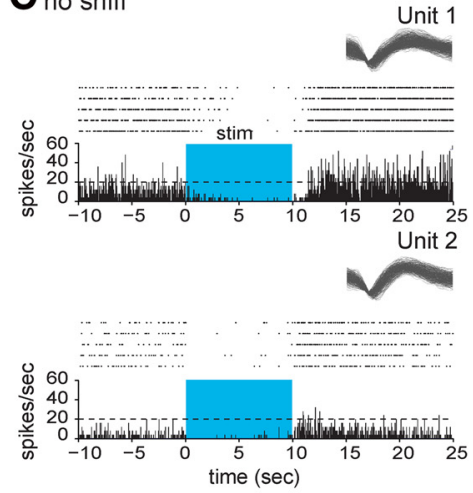

$\mathbf{F}$ sniff, no odor
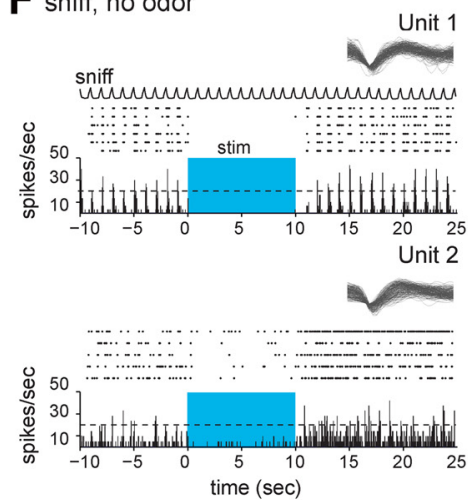

I sniff

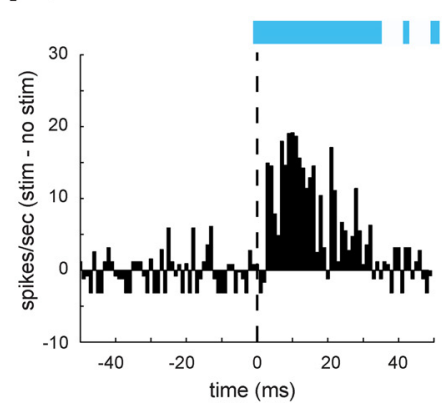

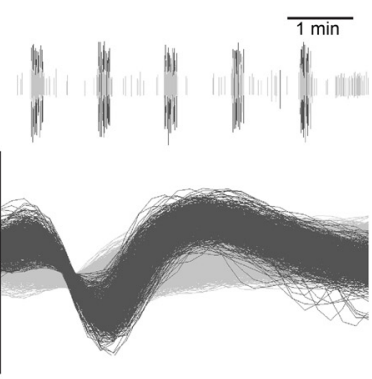

D

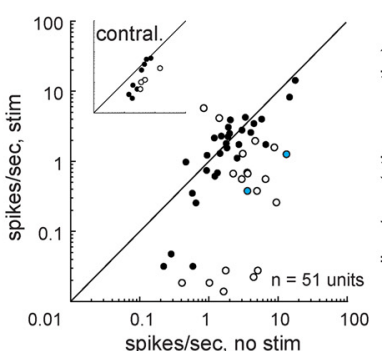

G

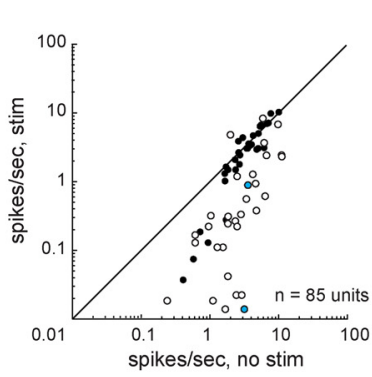

H

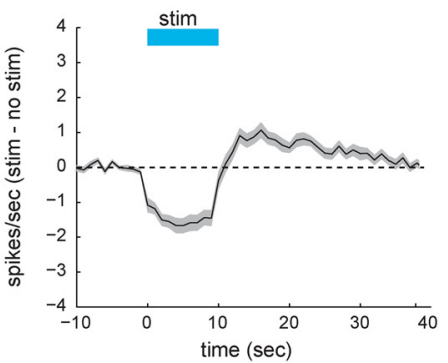

K

J

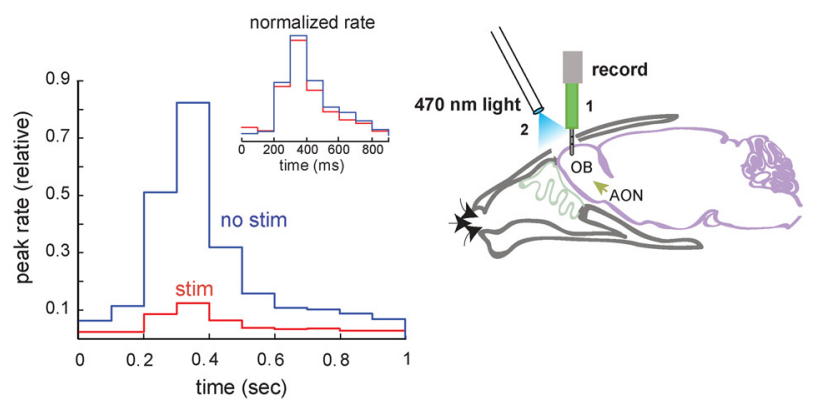

Figure 6. Optogenetic activation of AON axons in the OB inhibits spontaneous and inhalation-evoked MTC spiking. $\boldsymbol{A}$, Top, Exemplary recording of digitized spike waveforms from presumptive MTCs, both with a clear odor response. For unit classification (e.g., the degree of sniff modulation; see Materials and Methods), odorants were applied before the optogenetic stimulation experiments (no sniff, sniff, odor). Action potential waveforms with a signal-to-noise ratio of at least 4 SD above baseline were saved to a disk (sample rate $24 \mathrm{kHz}$ ) and further isolated using offline spike sorting. Bottom left, Isolation of waveforms into two different units by principal components 1 and 2. Bottom right, Spike waveforms of the isolated units. $B$, Exemplary interspike intervals (ISI). Top, ISI distribution of a single-unit. Inset, Sniff-triggered spike histogram of MTC spikes aligned to the start of inhalation depicting clear sniff modulation. Bottom, ISI distribution of a multi-unit. Many events were detected at intervals $<2 \mathrm{~ms}$ and are therefore in violation of the refractory period for a single neuron. Inset, Sniff-triggered spike histogram of the same unit showing no sniff modulation. C, Raster plot and spike histogram of spontaneous spiking of two presumptive MTCs in the absence of inhalation (no sniff condition). The spike rate was calculated per $100 \mathrm{~ms}$ bin. Spike rate decrease during optical stimulation of the dorsal OB ("stim," blue-shaded box). Inset, Spike waveform of the recorded units. D, Plot of spontaneous MTC firing activity in the $9 \mathrm{~s}$ prior ("no stim") and during light stimulation ("stim") for all tested units ( $n=51,8$ mice). Firing activity of most units was reduced during photostimulation. All units were subjected to a unit-by-unit test for significant effects of AON stimulation. Open circles represent units that showed significant light-evoked changes. Blue filled circles represent example units in C. Nine showed a statistically significant reduction in firing rate, and only two showed an increase. Inset, Spiking activity was also reduced when exclusively stimulating AON-derived fibers in the contralateral $O B$ in unilateral injected animals ( $n=13$ units from 2 mice). $\boldsymbol{E}$. Time course of light-evoked (blue bar) changes in spontaneous MTC firing (mean \pm SEM across all units). Trace represents change in mean spike rate in $1 \mathrm{~s}$ bins relative to the mean rate before stimulation. The time axis is relative to time of stimulation onset. A clear reduction in spiking activity 
the population of recorded presumptive MTCs ( $n=55$ units, from 6 mice), AON axon stimulation significantly decreased MTC odor activity (Fig. 7A-C), with a decrease from $4.02 \pm 2.37$ spikes/sniff/s (median \pm SD) during odorant presentation alone to $2.95 \pm 2.96$ spikes/sniff/s during odorant paired with light $\left(p=1.55 \times 10^{-4}\right.$, Wilcoxon signed rank test). Optical stimulation also decreased the odorant-evoked component of the MTC response when evaluated on a single-cell level (measured as $\Delta$ spikes/sniff/s relative to pre-odor presentation; Fig. $7 B$ ). Tested on a unit-by-unit basis, 19 of the 55 recorded cells (35\%) showed a significant change in odor-evoked spiking; 17 of those cells showed a significant decrease, only 2 showed an increase. The median decrease in spike rate, across the 17 cells found to be significantly inhibited, was 2.64 spikes/sniff/s (from $3.42 \pm 1.84$ to $0.78 \pm 1.15)$. As with effects on spontaneous spiking, the reduction of odorant-evoked MTC responses occurred rapidly and persisted for the duration of optical stimulation. The light-mediated inhibition was followed by an increase in spiking that lasted for $<25 \mathrm{~s}$ after the end of optical stimulation (Fig. 7A, Units 1 and 2; Fig. 7C). As with inhalation-evoked MTC responses, no change in the temporal component of MTC odor responses could be observed (Fig. $7 D$, inset; $p=0.6$, paired $t$ test comparing time bin of the peak of odorant-evoked firing rate for baseline versus optical stimulation; $n=55$ units from 6 mice). Optical stimulation resulted in an uniform spike reduction across the sniff cycle (Fig. 7D). Overall, this shows that activating AON axons strongly reduces not only MTC spontaneous activity but also sensory-evoked responses.

Finally, we tested how AON modulates MTC activity across multiple odorants. Thus, in a separate set of experiments, we measured responses of the same MTC to multiple odorants (for odorant panel, see Materials and Methods) with and without optogenetic activation of AON bulbar input (75 units, 3 animals, 375 cell-odor pairs). Odorant-evoked spike rates uniformly decreased during light stimulation for the example unit (Fig. $7 F$ ) as well as for the average across all recorded units (Fig. $7 G$ ).

$\leftarrow$

can be observed during optical stimulation. $\boldsymbol{F}$, Raster plot and spike histogram of MTC spiking during inhalation of clean air and optical stimulation (blue shaded area). Inhalation-evoked spike rates decreased during optical stimulation. Inset, Spike waveform of the recorded units. G, Plot of inhalation-evoked spontaneous MTC spiking in the $9 \mathrm{~s}$ prior ("no stim") and during light stimulation ("stim") for all tested units ( $n=85,10$ mice). Firing activity of most units was reduced during photostimulation. Open circles represent units that showed significant light-evoked changes in firing activity when tested on a unit-by-unit basis. Blue filled circles represent example units in $\boldsymbol{F}$. A total of 52 units showed a significant decrease in spikes per sniff; only two units showed an increase. $\boldsymbol{H}$, Time course of stimulation-evoked changes in inhalation-evoked MTC spiking. Spiking activity is strongly reduced during optical stimulation. I, Optogenetic AON stimulation elicits fast but brief excitatory responses in MTC. Time course of changes in spontaneous firing rate $50 \mathrm{~ms}$ before and $50 \mathrm{~ms}$ after the start of the optical stimulation during ongoing inhalation (sniff) show that optogenetic AON stimulation elicits fast but brief excitatory responses in MTC. The mean firing rate of all recorded units ( $n=85$ units, 10 mice) during the $1 \mathrm{~ms}$ time bins is depicted as spikes/s (stim - no stim). In the first milliseconds of optical stimulation, MTCs show an increase in spontaneous spiking. J, Snifftriggered spike histogram of inhalation-evoked MTC spiking aligned to the start of inhalation of clean air before (blue) and during (red) optical stimulation, normalized to the maximum bin in the no-stimulation condition. Bin width, $100 \mathrm{~ms}$. The histogram is compiled from significant units, with firing rate normalized separately for each unit. Optical stimulation strongly reduced peak spike rate. Inset, Sniff-triggered spike histogram normalized to the maximum and minimum bin for the two conditions independently. No change in spiking dynamics after $O B$ stimulation was observed. $\boldsymbol{K}$, Schematic of experimental approach. (1) 16channel silicon probe. (2) Optical fiber. Optical stimulation was performed at the level of the $O B$ to selectively target AON axonal projections to this area (for details, see Materials and Methods).
AON-mediated reduction of MTC sensory responses was homogeneous across the different odorants tested (Fig. $7 E ; p=0.22$, Kruskal-Wallis test); $68 \%$ of cell-odor pairs (255 cell-odor pairs) even exhibited an inhibition below pre-odor baseline firing rates. Only $2.6 \%$ (10 of the 375 cell-odor pairs) showed an increase $(>1 \Delta$ spike/s) in odorant-evoked spike rates during AON activation (Fig. $7 H$ ). Thus, the AON strongly inhibits sensory-evoked responses across odorants similar to what we observed in the behavioral experiments.

\section{Optogenetic AON activation reduces odorant-evoked MTC activity in awake mice}

To further elucidate the mechanism behind the suppression of licking response observed in the behavioral experiments, we conducted multitetrode recordings and optical AON stimulation in awake mice. MTAs with 32 recording channels were chronically implanted in the $\mathrm{OB}$ of 3 mice injected with AAV-ChR2-EYFP into the AON (Fig. 8A). Odorants were either presented alone or in combination with AON photostimulation. While odorant responses across the population of recorded presumptive MTCs ( $n=61$ units, from 3 mice, 10 sessions total) were generally sparse, AON stimulation significantly decreased sensory-evoked MTC activity (Fig. 8C; decrease from 9.22 \pm 7.61 spikes/s [median $\pm \mathrm{SD}$ ] during odorant presentation alone to $5.73 \pm 6.43$ spikes/s during odorant paired with light, $p=1.05 \times 10^{-5}$, Wilcoxon signed rank test). Optical stimulation also reduced MTC activity when evaluated on a single-cell level (measured as $\Delta$ spikes/s relative to pre-odor presentation) (Fig. $8 D$ ). Tested on a unit-by-unit basis, 35 of the 61 recorded units (57\%) showed a significant decrease in odor-evoked spiking.

In summary, our results point to AON-mediated MTC suppression as at least one mechanism underlying the strong behavioral response elicited by optogenetic AON stimulation.

\section{Discussion}

The AON is the most anterior part of olfactory cortex, lying directly behind the $\mathrm{OB}$, and constitutes its largest source of cortical projections. Despite these prominent features, the role of AON in odorant processing as well as the behavioral consequences of its activation have been sparingly investigated. Since the AON itself has been proposed as the first stage of odorant feature convergence, receiving structured sensory information in a bottom-up fashion and coding itself for odor objects (Haberly, 2001), we first tested whether AON photostimulation can be perceived as a sensory equivalent cue, similar to what has been reported for other sensory-processing areas (O'Connor et al., 2013; Guo et al., 2015). In contrast to the predictions from Haberly (2001), optogenetic AON stimulation does not elicit a behavioral response in animals trained to report the presence of odorants. Pairing optical stimulation with odor presentation reliably suppressed odorant responses of awake freely behaving mice. Mice trained to report the absence of odorants, however, did not lick in odor + AON stimulation trials. This suggests that optogenetic AON stimulation does not completely block odor perception, at least not to such an extent that mice would confuse it with no-odor trials. Still, the change in perception we are causing by AON stimulation seems to be so profound that mice do not perceive an odorant as a go stimulus anymore. This is true over a range of concentrations and stimulation regimens. Future studies are aimed at revealing the nature of this AON-mediated effect on odor perception. 
A

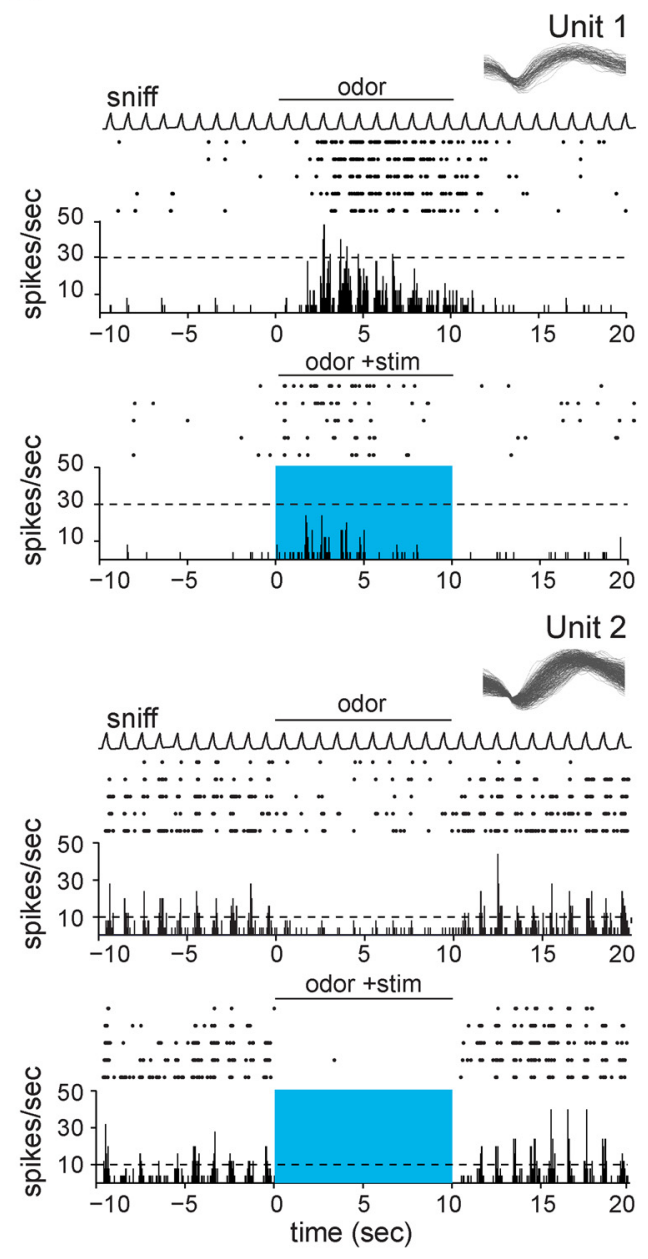

$\mathbf{F}$

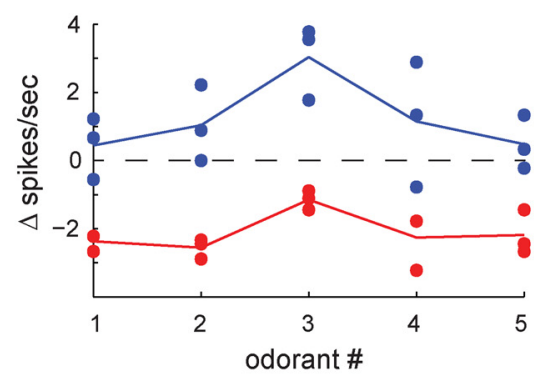

B
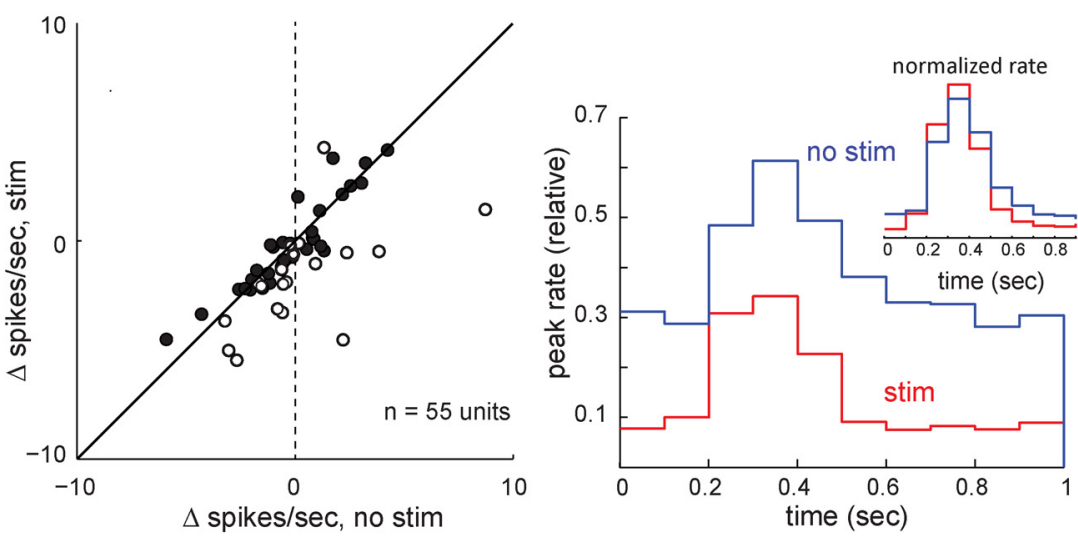

E
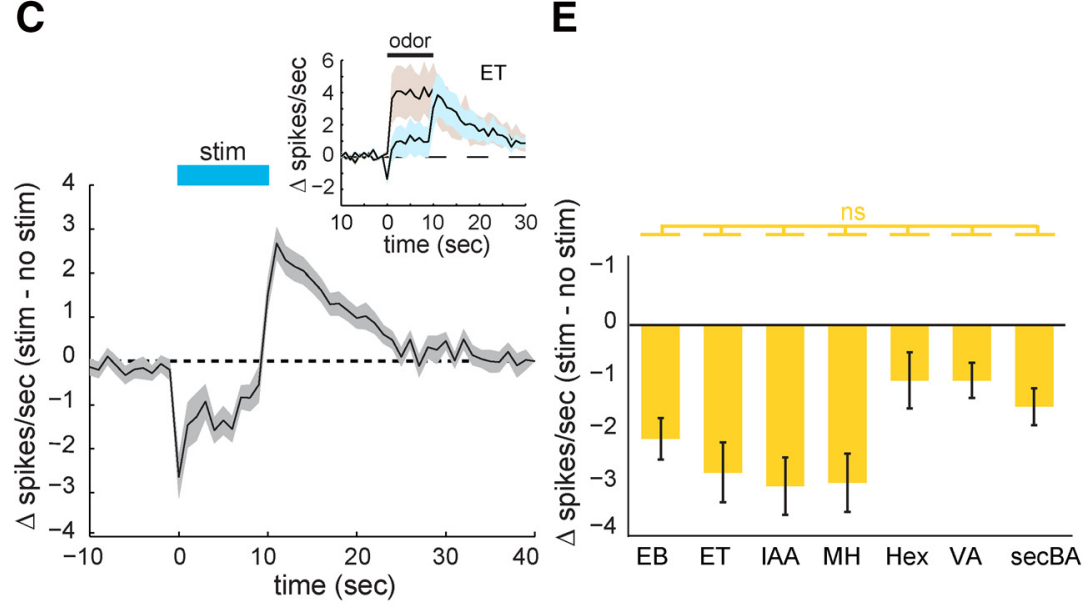

G

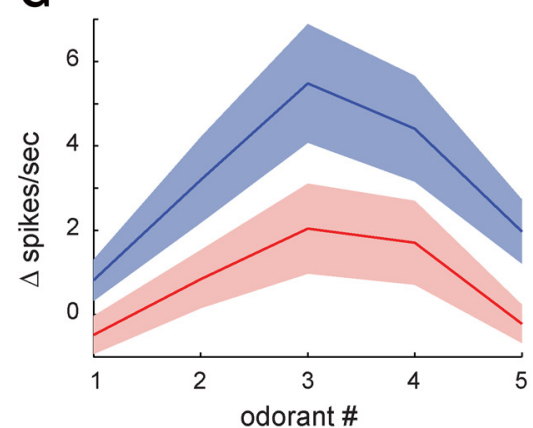

H

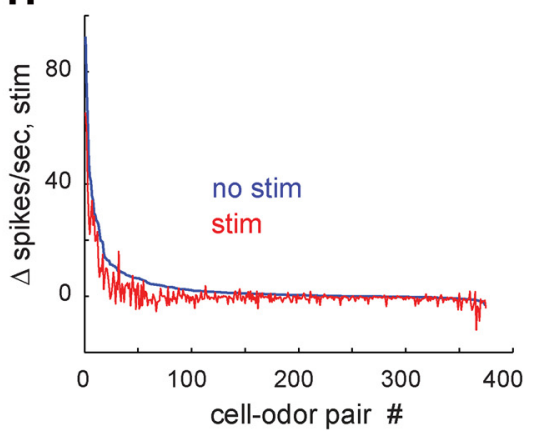

Figure 7. Optogenetic activation of AON axons in the OB inhibits odor-evoked MTC spiking. $A$, Odorant-evoked MTC spiking is suppressed by optical OB stimulation for neurons that show an excitation (Unit 1, top) or suppression (Unit 2, bottom) of firing rate in response to odorant presentation. Inset, Spike waveform of the recorded units. $\boldsymbol{B}$, Plot of odorant-evoked changes in MTC spiking activity ( $\Delta$ spikes/sniff) in the absence ("no stim") and during ("stim") photostimulation ( $n=55,6$ mice). Open circles represent units that showed significant light-evoked changes in firing activity when tested on a unit-by-unit basis. Seventeen of those cells showed a significant decrease; only two showed an increase. $\boldsymbol{C}$, Time course of the effect of AON fiber activation on odor-evoked MTC spiking, averaged across all units. Shaded area represents the variance ( \pm SEM) around mean. Blue bar represents the time of optical stimulation and simultaneous odorant presentation. Photostimulation leads to a strong reduction of odorant-evoked firing activity. Inset, Changes in odor (ET) evoked spiking with (light blue) and without optical stimulation (brown). D, Sniff-triggered spike histogram of odorant-evoked MTC spiking during odorant presentation in baseline conditions ("no stim," blue) and during ("stim," red) optical OB stimulation. Inset, Sniff-triggered spike histogram normalized to the maximum and minimum bin for the two conditions independently. $\boldsymbol{E}$, Light-evoked changes of odorant-evoked MTC activity for all tested odorants. $\boldsymbol{F}$, Effect of OB optical stimulation on odorant response spectrum for an example MTC tested with five odorants. Blue represents baseline response. Red represents response during optical stimulation. Odorants are ordered with the strongest excitatory response in the baseline condition in the middle of the abscissa. The effect of optical stimulation varies with odorant but is always inhibitory. Circles represent firing rates for each trial. Lines connect median responses across all tested trials. $\mathbf{G}$, Effect of OB optical stimulation on odorant response spectrum averaged across all recorded MTCs. Blue represents baseline response. Red represents response during optical stimulation. Odorants are ordered separately for each unit, with the strongest excitatory response in the baseline condition in the middle of the abscissa. Odorant-evoked spike rates uniformly decreased during light stimulation. Lines connect median responses. Shaded areas represent the variance (SEM). $\boldsymbol{H}$, Odorant response magnitudes ( $\Delta$ spikes/s) plotted for baseline (blue) and optical stimulation (red) as a function of cell identity, sorted in order of magnitude of excitatory response in baseline conditions. Most units show a decrease in odorant-evoked excitation, including those that are suppressed during odorant presentation. 
The obtained results might point toward the AON as an important modulator of odor perception rather than being a pure odor-encoding region. In concordance to the behavior data, we could show that activation of AON in the anesthetized animal elicits a strong inhibition of MTC firing on spontaneous as well as on sensory-evoked activity and provide proof of concept evidence of an AONmediated inhibition of MTC output in awake animals, making this the first report of matching physiological and behavioral changes in sensory-evoked responses using fast, timely controlled optogenetics for the AON so far.

\section{Optogenetic stimulation of AON}

Optogenetic activation was achieved through viral ChR2(H134R)-EYFP expression in the $A O N$ of nicotinic receptor $\alpha 7$ (Chrna7)-Cre mice (Rogers et al., 2012b). As shown previously (Rothermel and Wachowiak, 2014), this approach labels a substantial amount of cells within the AON that correspond with morphologic descriptions of principal cells (Brunjes and Kenerson, 2010). Here, we were able to show a wide overlap ( $\sim 60 \%)$ of Cre-expressing cells and CaMKII, a marker for principle AON neurons (Libbrecht et al., 2018). While only few Cre-expressing neurons express the inhibitory marker GAD, we can only speculate about the identity of the remaining cells since information on the cellular AON composition is sparse (Kay and Brunjes, 2014).

Expression of Cre-dependent constructs could be observed in all AON areas, including pars externa. Recently, it was shown that a subpopulation of AON neurons, AON pars externa, can elicit EPSPs in contralateral OB mitral cells (Grobman et al., 2018). In our experiments, we rarely observe excitatory MTC responses in response to AON stimulation (beyond the first few milliseconds). While we cannot rule out that these rare excitatory effects are because of weak AON pars externa stimulation, or reflecting differential AON effects on different OB output types (mitral vs tufted cells), we argue that the dominant inhibitory response observed in our study is likely mediated by AON pars principalis because of intense viral expression, and the AON fiber placement in this area.

Optogenetic stimulation in anesthetized electrophysiological recordings was performed at the level of the OB to exclude disynaptic or even polysynaptic effects from other targets of AON projections. In behavior experiments, optogenetic stimulation had to be performed at the level of the AON to exclude insufficient photostimulation, since even monomolecular odorants elicit complex OB activity pattern (Johnson and Leon, 2007; Johnson et al., 2009; Ma et al., 2012; Baker et al., 2019), and stimulation of just the dorsally located AON fibers in the OB would most probably have yielded false-negative results. However, like the behavioral experiments, the awake electrophysiological recordings were performed using direct $\mathrm{AON}$ stimulation.
B

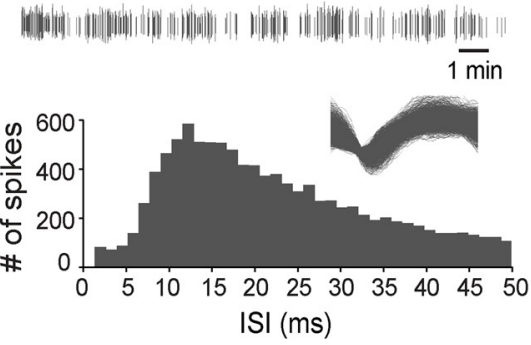

D

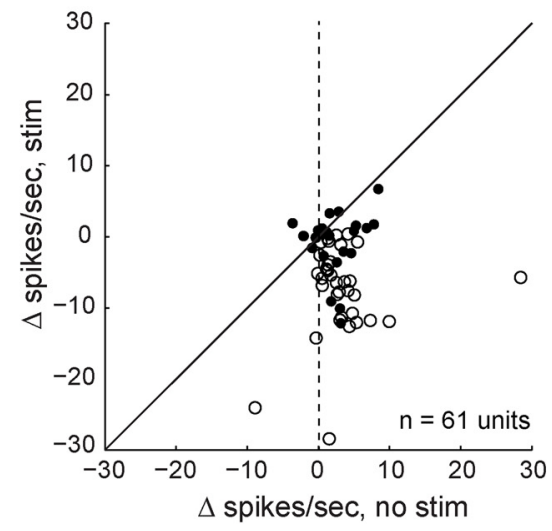

Recoding MTC activity in the anesthetized or awake condition, using either $\mathrm{AON}$ OB fiber or direct $\mathrm{AON}$ stimulation, caused a significant inhibition of spontaneous as well as odor-evoked firing in $\mathrm{OB}$ output neurons. It might seem surprising that this inhibition is not larger given the strong impact of AON stimulation on behavior. While more MTCs show a significant suppression in the awake versus the anesthetized condition (57\% vs $35 \%)$ pointing to state-dependent effects, the incomplete inhibition of the MTC population might also imply the importance of other structures in mediating AON-caused modulations on odor perception, such as piriform cortex, olfactory tubercle, or hippocampus, which are intensely connected with the AON (Haberly and Price, 1978; Davis and Macrides, 1981; Luskin and Price, 1983; Aqrabawi and Kim, 2018a). During optogenetic stimulation, we did not observe changes in running behavior or accuracy in nonolfactory tasks. Although these findings render it unlikely, we cannot rule out that task performance could be affected by other components (e.g., motor or memory function). Future experiments will address the contribution of $\mathrm{OB}$ output inhibition to behavioral suppression in more detail.

\section{Circuit mechanisms underlying AON modulation}

Since AON-derived back projections to the $\mathrm{OB}$ are glutamatergic, reports of inhibitory AON modulation effects seem counterintuitive. The circuit mechanisms underlying the strong inhibitory effects by glutamatergic AON fibers on MTCs in the $\mathrm{OB}$ remain to be elucidated. Projections from $\mathrm{AON}$ to $\mathrm{OB}$ are 
diverse in terms of source, and their exact targets in the $\mathrm{OB}$ are still not fully known (for review, see Brunjes et al., 2005). In our experiments, expression was predominately observed in the granule cell and external plexiform $\mathrm{OB}$ layers, reaching up to the border of the glomerular layer, consistent with earlier characterizations of AON-OB projections (Reyher et al., 1988). This projection pattern as well as in vitro results from Markopoulos et al. (2012), suggest disynaptically mediated inhibition via inhibitory periglomerular neurons in the periglomerular layer and/or granule cells in the granule cell layer.

The AON has been shown to send projections to the ipsilateral as well as to the contralateral OB (Schoenfeld and Macrides, 1984; Shipley and Adamek, 1984; Kay and Brunjes, 2014). In most of our electrophysiological experiments, we were unable to distinguish between effects elicited from ipsilateral or contralateral AON projections because of the bilateral injections performed in these animals. However, optogenetically stimulating fibers in the contralateral $\mathrm{OB}$ after unilateral $\mathrm{AON}$ injection in a subset of electrophysiological experiments revealed inhibitory effects qualitatively similar to those in bilaterally injected animals. Since contralaterally projecting fibers predominantly target the granule cell layer (Davis and Macrides, 1981; Reyher et al., 1988; Markopoulos et al., 2012; Rothermel and Wachowiak, 2014), these findings, as well as the strong inhibition seen in behavioral experiments with unilateral AON stimulation, point to granule cells being the major mediators of cortically derived inhibition in the $\mathrm{OB}$, in accordance with findings from previous studies (Boyd et al., 2012; Markopoulos et al., 2012).

\section{Functional role of modulating AON activity}

Our experiments show that the inhibitory influence of $A O N$ on olfactory behavior can be very strong. Inhibition in the $\mathrm{OB}$ has been proposed as a mechanism to sharpen the odor tuning of MTC (Yokoi et al., 1995); however, the observed uniform inhibition of all odorant responses within a unit is not consistent with an AON-mediated sharpening of odor responses. Optical stimulation is likely stronger and spatiotemporally more homogeneous compared with "intrinsic" AON activity. Despite the large range of functions the AON is associated with (Rajan et al., 2006; Yan et al., 2008; Kikuta et al., 2010; Soria-Gomez et al., 2014; Oettl et al., 2016; Padmanabhan et al., 2016; Esquivelzeta Rabell et al., 2017; Aqrabawi and Kim, 2018b; Grobman et al., 2018), activity in the AON is poorly characterized, especially in terms of sensory evoked activity or as a result of its input from upstream areas, such as anterior piriform cortex (Haberly and Price, 1978; Luskin and Price, 1983; Haberly, 2001; Hagiwara et al., 2012), amygdala (De Carlos et al., 1989; Gomez and Newman, 1992; Canteras et al., 1995; Petrovich et al., 1996), basal forebrain (Broadwell and Jacobowitz, 1976; Luiten et al., 1987; De Carlos et al., 1989; Carnes et al., 1990; Gaykema et al., 1990; Zaborszky et al., 2012; Gielow and Zaborszky, 2017), hippocampus (Swanson and Cowan, 1977; van Groen and Wyss, 1990; Aqrabawi and Kim, 2018a), or mPFC (Sesack et al., 1989). Thus, speculation about more "naturalistic" activity and stimulation of AON is complicated and certainly out of the scope of this study. The fact that AON-derived fibers in the $\mathrm{OB}$ are activated in an odorant-specific manner (Rothermel and Wachowiak, 2014) certainly speaks for AON-dependent modulation acting in a specific and fine-tuned way. Assuming a more "specific" activity in AON top-down fibers, very distinct inhibitory processes within the OB could be supported, such as fast adaptation or adjusting the dynamic range of MTCs to strong odorants, rather than a complete disruption of sensory responses. Additionally, there might also be "state-dependent" AON activation by higher brain areas, which might be spatiotemporally much broader, thereby potentially more closely reflecting the here applied optical stimulation. In line with our results, activation of a subregion of the AON (medial AON, potentially driven by hippocampal inputs) using a chemogenetic approach was recently reported to reduce olfactory sensitivity as well as to impair the performance of olfaction-dependent behaviors (Aqrabawi et al., 2016). However, because of the slow nature of the chemogenetic approach, the temporal component of this effect could not be investigated.

In conclusion, our results demonstrate the strong modulatory potential of the AON on odor responses. We show that AON stimulation in awake mice suppresses odor responses regardless of odor identity or odor concentration. Furthermore, AON activation elicited a strong inhibition of spontaneous as well as odorevoked MTC firing in the anesthetized animals with even strongly odorant-activated units being inhibited below pre-odor baseline firing rates. Together, our study provides the first report of matching physiological and behavioral changes in sensoryevoked responses using fast, timely controlled optogenetics for the $\mathrm{AON}$ and implicates the $\mathrm{AON}$ as a potential gatekeeper of olfactory information.

\section{References}

Aqrabawi AJ, Kim JC (2018a) Topographic organization of hippocampal inputs to the anterior olfactory nucleus. Front Neuroanat 12:12.

Aqrabawi AJ, Kim JC (2018b) Hippocampal projections to the anterior olfactory nucleus differentially convey spatiotemporal information during episodic odour memory. Nat Commun 9:2735.

Aqrabawi AJ, Kim JC (2020) Olfactory memory representations are stored in the anterior olfactory nucleus. Nat Commun 11:1246.

Aqrabawi AJ, Browne CJ, Dargaei Z, Garand D, Khademullah CS, Woodin MA, Kim JC (2016) Top-down modulation of olfactory-guided behaviours by the anterior olfactory nucleus pars medialis and ventral hippocampus. Nat Commun 7:13721.

Baker KL, Vasan G, Gumaste A, Pieribone VA, Verhagen JV (2019) Spatiotemporal dynamics of odor responses in the lateral and dorsal olfactory bulb. PLoS Biol 17:e3000409.

Boyd AM, Sturgill JF, Poo C, Isaacson JS (2012) Cortical feedback control of olfactory bulb circuits. Neuron 76:1161-1174.

Boyd AM, Kato HK, Komiyama T, Isaacson JS (2015) Broadcasting of cortical activity to the olfactory bulb. Cell Rep 10:1032-1039.

Bozza T, McGann JP, Mombaerts P, Wachowiak M (2004) In vivo imaging of neuronal activity by targeted expression of a genetically encoded probe in the mouse. Neuron 42:9-21.

Broadwell RD, Jacobowitz DM (1976) Olfactory relationships of the telencephalon and diencephalon in the rabbit: III. The ipsilateral centrifugal fibers to the olfactory bulbar and retrobulbar formations. J Comp Neurol 170:321-345.

Brunjes PC, Illig KR, Meyer EA (2005) A field guide to the anterior olfactory nucleus (cortex). Brain Res Brain Res Rev 50:305-335.

Brunjes PC, Kenerson MC (2010) The anterior olfactory nucleus: quantitative study of dendritic morphology. J Comp Neurol 518:1603-1616.

Canteras NS, Simerly RB, Swanson LW (1995) Organization of projections from the medial nucleus of the amygdala: a PHAL study in the rat. J Comp Neurol 360:213-245.

Carey RM, Wachowiak M (2011) Effect of sniffing on the temporal structure of mitral/tufted cell output from the olfactory bulb. J Neurosci 31:1061510626.

Carey RM, Verhagen JV, Wesson DW, Pirez N, Wachowiak M (2009) Temporal structure of receptor neuron input to the olfactory bulb imaged in behaving rats. J Neurophysiol 101:1073-1088.

Carnes KM, Fuller TA, Price JL (1990) Sources of presumptive glutamatergic/aspartatergic afferents to the magnocellular basal forebrain in the rat. J Comp Neurol 302:824-852.

Carson KA (1984) Quantitative localization of neurons projecting to the mouse main olfactory bulb. Brain Res Bull 12:629-634. 
Choi GB, Stettler DD, Kallman BR, Bhaskar ST, Fleischmann A, Axel R (2011) Driving opposing behaviors with ensembles of piriform neurons. Cell 146:1004-1015.

Courtiol E, Amat C, Thevenet M, Messaoudi B, Garcia S, Buonviso N (2011) Reshaping of bulbar odor response by nasal flow rate in the rat. PLoS One 6:e16445.

Davis BJ, Macrides F (1981) The organization of centrifugal projections from the anterior olfactory nucleus, ventral hippocampal rudiment, and piriform cortex to the main olfactory bulb in the hamster: an autoradiographic study. J Comp Neurol 203:475-493.

De Carlos JA, Lopez-Mascaraque L, Valverde F (1989) Connections of the olfactory bulb and nucleus olfactorius anterior in the hedgehog (Erinaceus europaeus): fluorescent tracers and HRP study. J Comp Neurol 279:601618.

Dominguez del Toro E, Juiz JM, Peng X, Lindstrom J, Criado M (1994) Immunocytochemical localization of the alpha 7 subunit of the nicotinic acetylcholine receptor in the rat central nervous system. J Comp Neurol 349:325-342.

Eiting TP, Wachowiak M (2018) Artificial inhalation protocol in adult mice. Bio Protoc 8:e3024.

Esquivelzeta Rabell J, Mutlu K, Noutel J, Martin Del Olmo P, Haesler S (2017) Spontaneous rapid odor source localization behavior requires interhemispheric communication. Curr Biol 27:1542-1548.e1544.

Gahring LC, Enioutina EY, Myers EJ, Spangrude GJ, Efimova OV, Kelley TW, Tvrdik P, Capecchi MR, Rogers SW (2013) Nicotinic receptor alpha7 expression identifies a novel hematopoietic progenitor lineage. PLoS One 8:e57481.

Gaykema RP, Luiten PG, Nyakas C, Traber J (1990) Cortical projection patterns of the medial septum-diagonal band complex. J Comp Neurol 293:103-124.

Gielow MR, Zaborszky L (2017) The input-output relationship of the cholinergic basal forebrain. Cell Rep 18:1817-1830.

Gomez DM, Newman SW (1992) Differential projections of the anterior and posterior regions of the medial amygdaloid nucleus in the Syrian hamster. J Comp Neurol 317:195-218.

Grobman M, Dalal T, Lavian H, Shmuel R, Belelovsky K, Xu F, Korngreen A, Haddad R (2018) A mirror-symmetric excitatory link coordinates odor maps across olfactory bulbs and enables odor perceptual unity. Neuron 99:800-813.e806.

Grosmaitre X, Santarelli LC, Tan J, Luo M, Ma M (2007) Dual functions of mammalian olfactory sensory neurons as odor detectors and mechanical sensors. Nat Neurosci 10:348-354.

Guo W, Hight AE, Chen JX, Klapoetke NC, Hancock KE, ShinnCunningham BG, Boyden ES, Lee DJ, Polley DB (2015) Hearing the light: neural and perceptual encoding of optogenetic stimulation in the central auditory pathway. Sci Rep 5:10319.

Haberly LB (2001) Parallel-distributed processing in olfactory cortex: new insights from morphological and physiological analysis of neuronal circuitry. Chem Senses 26:551-576.

Haberly LB, Price JL (1978) Association and commissural fiber systems of the olfactory cortex of the rat. J Comp Neurol 178:711-740.

Hagiwara A, Pal SK, Sato TF, Wienisch M, Murthy VN (2012) Optophysiological analysis of associational circuits in the olfactory cortex. Front Neural Circuits 6:18.

Histed MH, Ni AM, Maunsell JH (2013) Insights into cortical mechanisms of behavior from microstimulation experiments. Prog Neurobiol 103:115130

Illig KR, Eudy JD (2009) Contralateral projections of the rat anterior olfactory nucleus. J Comp Neurol 512:115-123.

Johnson BA, Leon M (2007) Chemotopic odorant coding in a mammalian olfactory system. J Comp Neurol 503:1-34.

Johnson BA, Xu Z, Ali SS, Leon M (2009) Spatial representations of odorants in olfactory bulbs of rats and mice: similarities and differences in chemotopic organization. J Comp Neurol 514:658-673.

Kay RB, Brunjes PC (2014) Diversity among principal and GABAergic neurons of the anterior olfactory nucleus. Front Cell Neurosci 8:111.

Kikuta S, Sato K, Kashiwadani H, Tsunoda K, Yamasoba T, Mori K (2010) Neurons in the anterior olfactory nucleus pars externa detect right or left localization of odor sources. Proc Natl Acad Sci USA 107:12363-12368.

Lei H, Mooney R, Katz LC (2006) Synaptic integration of olfactory information in mouse anterior olfactory nucleus. J Neurosci 26:12023-12032.
Levinson M, Kolenda JP, Alexandrou GJ, Escanilla O, Cleland TA, Smith DM, Linster C (2020) Context-dependent odor learning requires the anterior olfactory nucleus. Behav Neurosci 134:332-343.

Lewicki MS (1998) A review of methods for spike sorting: the detection and classification of neural action potentials. Network 9:R53-R78.

Libbrecht S, Hoffman L, Welkenhuysen M, Van den Haute C, Baekelandt V, Braeken D, Haesler S (2018) Proximal and distal modulation of neural activity by spatially confined optogenetic activation with an integrated high-density optoelectrode. J Neurophysiol 120:149-161.

Luiten PG, Gaykema RP, Traber J, Spencer DG Jr (1987) Cortical projection patterns of magnocellular basal nucleus subdivisions as revealed by anterogradely transported Phaseolus vulgaris leucoagglutinin. Brain Res 413:229-250

Luskin MB, Price JL (1983) The topographic organization of associational fibers of the olfactory system in the rat, including centrifugal fibers to the olfactory bulb. J Comp Neurol 216:264-291.

Ma L, Qiu Q, Gradwohl S, Scott A, Yu EQ, Alexander R, Wiegraebe W, Yu CR (2012) Distributed representation of chemical features and tunotopic organization of glomeruli in the mouse olfactory bulb. Proc Natl Acad Sci USA 109:5481-5486.

Markopoulos F, Rokni D, Gire DH, Murthy VN (2012) Functional properties of cortical feedback projections to the olfactory bulb. Neuron 76:11751188.

O'Connor DH, Hires SA, Guo ZV, Li N, Yu J, Sun QQ, Huber D, Svoboda K (2013) Neural coding during active somatosensation revealed using illusory touch. Nat Neurosci 16:958-965.

Oettl LL, Ravi N, Schneider M, Scheller MF, Schneider P, Mitre M, da Silva Gouveia M, Froemke RC, Chao MV, Young WS, Meyer-Lindenberg A, Grinevich V, Shusterman R, Kelsch W (2016) Oxytocin enhances social recognition by modulating cortical control of early olfactory processing. Neuron 90:609-621.

Oettl LL, Scheller M, Wieland S, Haag F, Wolf D, Loeb C, Ravi N, Durstewitz D, Shusterman R, Russo E, Kelsch W (2019) Phasic dopamine enhances the distinct decoding and perceived salience of stimuli. Nat Commun 11:3460.

Otazu GH, Chae H, Davis MB, Albeanu DF (2015) Cortical feedback decorrelates olfactory bulb output in awake mice. Neuron 86:1461-1477.

Padmanabhan K, Osakada F, Tarabrina A, Kizer E, Callaway EM, Gage FH, Sejnowski TJ (2016) Diverse representations of olfactory information in centrifugal feedback projections. J Neurosci 36:7535-7545.

Petrovich GD, Risold PY, Swanson LW (1996) Organization of projections from the basomedial nucleus of the amygdala: a PHAL study in the rat. J Comp Neurol 374:387-420.

Rajan R, Clement JP, Bhalla US (2006) Rats smell in stereo. Science 311:666670.

Reyher CK, Schwerdtfeger WK, Baumgarten HG (1988) Interbulbar axonal collateralization and morphology of anterior olfactory nucleus neurons in the rat. Brain Res Bull 20:549-566.

Rogers SW, Gahring LC (2012) Nicotinic receptor alpha7 expression during tooth morphogenesis reveals functional pleiotropy. PLoS One 7:e36467.

Rogers SW, Myers EJ, Gahring LC (2012a) The expression of nicotinic receptor alpha7 during cochlear development. Brain Behav 2:628-639.

Rogers SW, Tvrdik P, Capecchi MR, Gahring LC (2012b) Prenatal ablation of nicotinic receptor alpha7 cell lineages produces lumbosacral spina bifida the severity of which is modified by choline and nicotine exposure. Am J Med Genet A 158A:1135-1144.

Rothermel M, Wachowiak M (2014) Functional imaging of cortical feedback projections to the olfactory bulb. Front Neural Circuits 8:73.

Rothermel M, Brunert D, Zabawa C, Díaz-Quesada M, Wachowiak M (2013) Transgene expression in target-defined neuron populations mediated by retrograde infection with adeno-associated viral vectors. J Neurosci 33:15195-15206.

Rothermel M, Carey RM, Puche A, Shipley MT, Wachowiak M (2014) Cholinergic inputs from basal forebrain add an excitatory bias to odor coding in the olfactory bulb. J Neurosci 34:4654-4664.

Schoenfeld TA, Macrides F (1984) Topographic organization of connections between the main olfactory bulb and pars externa of the anterior olfactory nucleus in the hamster. J Comp Neurol 227:121-135.

Sesack SR, Deutch AY, Roth RH, Bunney BS (1989) Topographical organization of the efferent projections of the medial prefrontal cortex in the rat: an anterograde tract-tracing study with Phaseolus vulgaris leucoagglutinin. J Comp Neurol 290:213-242. 
Shipley MT, Adamek GD (1984) The connections of the mouse olfactory bulb: a study using orthograde and retrograde transport of wheat germ agglutinin conjugated to horseradish peroxidase. Brain Res Bull 12:669688.

Smear M, Resulaj A, Zhang J, Bozza T, Rinberg D (2013) Multiple perceptible signals from a single olfactory glomerulus. Nat Neurosci 16:1687-1691.

Soria-Gomez E, Bellochio L, Reguero L, Lepousez G, Martin C, Bendahmane M, Ruehle S, Remmers F, Desprez T, Matias I, Wiesner T, Cannich A, Nissant A, Wadleigh A, Pape HC, Chiarlone AP, Quarta C, Verrier D, Vincent P, Massa F, et al. (2014) The endocannabinoid system controls food intake via olfactory processes. Nat Neurosci 17:407-415.

Spors H, Wachowiak M, Cohen LB, Friedrich RW (2006) Temporal dynamics and latency patterns of receptor neuron input to the olfactory bulb. J Neurosci 26:1247-1259.

Swanson LW, Cowan WM (1977) An autoradiographic study of the organization of the efferent connections of the hippocampal formation in the rat. J Comp Neurol 172:49-84.

Valverde F, Lopez-Mascaraque L, De Carlos JA (1989) Structure of the nucleus olfactorius anterior of the hedgehog (Erinaceus europaeus). J Comp Neurol 279:581-600.

van Groen T, Wyss JM (1990) Extrinsic projections from area CA1 of the rat hippocampus: olfactory, cortical, subcortical, and bilateral hippocampal formation projections. J Comp Neurol 302:515-528.

Verhagen JV, Wesson DW, Netoff TI, White JA, Wachowiak M (2007) Sniffing controls an adaptive filter of sensory input to the olfactory bulb. Nat Neurosci 10:631-639.
Wachowiak M, Cohen LB (2001) Representation of odorants by receptor neuron input to the mouse olfactory bulb. Neuron 32:723-735

Wachowiak M, Economo MN, Díaz-Quesada M, Brunert D, Wesson DW, White JA, Rothermel M (2013) Optical dissection of odor information processing in vivo using GCaMPs expressed in specified cell types of the olfactory bulb. J Neurosci 33:5285-5300.

Wacker DW, Engelmann M, Tobin VA, Meddle SL, Ludwig M (2011) Vasopressin and social odor processing in the olfactory bulb and anterior olfactory nucleus. Ann NY Acad Sci 1220:106-116.

Wang CY, Liu Z, Ng YH, Sudhof TC (2020) A synaptic circuit required for acquisition but not recall of social transmission of food preference. Neuron 107:144-157.e4.

Wen P, Rao X, Xu L, Zhang Z, Jia F, He X, Xu F (2019) Cortical organization of centrifugal afferents to the olfactory bulb: mono- and trans-synaptic tracing with recombinant neurotropic viral tracers. Neurosci Bull 35:709-723

Wilson DA, Sullivan RM (2011) Cortical processing of odor objects. Neuron 72:506-519.

Yan Z, Tan J, Qin C, Lu Y, Ding C, Luo M (2008) Precise circuitry links bilaterally symmetric olfactory maps. Neuron 58:613-624.

Yokoi M, Mori K, Nakanishi S (1995) Refinement of odor molecule tuning by dendrodendritic synaptic inhibition in the olfactory bulb. Proc Natl Acad Sci USA 92:3371-3375.

Zaborszky L, Van den Pol AN, Gyengesi E (2012) The basal forebrain cholinergic projection system in mice. In: The mouse nervous system (Watson C, Paxinos G, Puelles L, eds), pp 684-718. Amsterdam: Elsevier. 